\title{
Beiträge zur Kenntniss der physiologisohen Farbenblindheit.*)
}

\author{
Von
}

Dr. Hugo Magnus,

Docent der Augenheilkunde an der Universität zu Breslau.

\section{\$1. Plan der Untersuchung.}

Mit Beginn des Wintersemesters $1877 / 78$ erhielten Prof. Cohn und ich auf unser Ersuchen von den königlichen und städtischen Schulbehörden Breslau's die Erlaubniss: in allen Schulen unserer Stadt, den öffentlichen wie auch den privaten, umfassende Untersuchungen des Farbensinnes bei Schülern und Schülerinnen vornehmen zu dürfen. Im Besitz dieser Erlaubniss begannen wir im November 1877 mit unseren Untersuchungen und zwar wurden dieselben nach einem gemeinsamen Plan, den wir vorher entworfen hatten, in Ausführung gebracht. Jeder von uns, Prof. Cohn sowie ich, hatten eine be-

*) Die beste bibliographische Uebersicht über die einschlägige Literatur findet man bei Jeffries, Dangers from Color-Blindness in railroad employés and pilots. Boston. 1878. p. 34-40. Wir machen auf diese Arbeit ganz besonders anfmerksam, da wir im Verlaut unserer Mittheilungen auf die Literatur nur insofern Rücksicht nehmen können, als wir sie für unsere Zwecke unmittelbar brauchen; und auch dabei müssen wir uns Beschränkung auferlegen. 
stimmte Anzahl von Schulen übernommen, in denen wir unter Grundlegung des vorher von uns verabredeten Planes, aber jeder selbstständig und völlig für sich, untersuchten. Die Untersuchung in der Schule selbst wurde, wenigstens von $\mathrm{mir}^{*}$ ), genau nach den Vorschriften ausgeführt, wie sie Holmgren**) in seinem bekannten Werk entworfen hat. Ich kann deshalb von einer eingehenderen Schilderung der in den Schulklassen von mir geübten Methode absehen, indem ich auf die erschöpfende und klare Darstellung, welche Holmgren selbst gegeben hat, hinweise. Alle Individuen, welche sich bei diesen Prüfungen Missgriffe zu schulden kommen liessen, indem sie zu der ihnen vorgelegten Probefarbe andersfarbige Wollenbündel aus dem Holmgren'schen Wollensortiment heraussuchten, wurden als der Farbenblindheit dringend verdächtig betrachtet und in unserer Behausung einer sehr eingehenden zweiten Prüfung unterzogen.

Auf diese Weise glaubten wir uns nicht allein gegen etwaige Täuschungen und Irrthümer sicher stellen, sondern auch die einzelnen Fälle durch Anwendung der verschiedensten Methoden auf das Eingehendste und Genaueste studiren zu können. Zugleich gewährte die Benutzung verschiedener Untersuchungsmethoden auch ein sicheres Urtheil und eine verlässliche Kritik über den Werth und die Leistungsfähigkeit einer jeden einzelnen Methode. Und da grade die Untersuchung des Farbensinnes in den letzten Jahren mit Recht ein allgemeines praktisches Interesse gewonnen hat und ron

*) Cohn hat, nach seinen Heidelberger Mittheilungen zu schliessen, die Probe I. der Holmgren'schen Methode, die mit grüner Wolle ausgefuhrt wird, weggelassen; wenigstens empfiehlt er zur Entdeckung der Farbenblindheit rosa Wolle und nicht grüne, wie dies aber gerade Holmgren vorschreibt.

**) Holmgren. De la cécité des couleurs dans ses rapports arec les chemins de fer et la marine. Stockholm und Paris 1878. 
den verschiedensten Bahnbehörden als unerlässlich ihrem Betrieb eingefūgt worden ist, so erschien die kritische Prüfung der einzelnen Methoden auf ihren Werth und ihre Leistungsfähigkeit durchaus geboten. Ja ich hoffe, dass die Breslauer Untersuchungen auf das Prüfungsverfahren bei den deutschen Bahnen einen gewissen Einfluss ausüben und, was dringend zu wünschen wäre, das Verfahren für ganz Deutschland zu einem einheitlichen und gleichmässigen gestalten mögen.

Bei dieser der allgemeinen Schuluntersuchung folgenden eingehenden Prüfung wurde der Farbenblinde, resp. das der Farbenblindheit verdächtige Individuum noch in folgender Weise untersucht:

1) Es wurden ihm farbige Pigmente und zwar intensiv gefärbte chemische Niederschläge, welche in kleinen Kräuschen aufbewahrt wurden, vorgelegt. Er musste die Farbe eines jeden Niederschlages nennen, sodann die gleichartigen Proben dazu heraussuchen und schliesslich dies Manöver auch noch mit Benutzung farbiger Brillen (roth, grün, blau, gelb) ausführen.

2) Wurde eine Prüfung unter Benutzung des Simultancontrastes vorgenommen. Dieselbe war eine doppelte, indem einmal farbige Schatten nach der Stilling'schen Methode benutzt wurden und dann noch der sogenannte Florconcontrast in Anwendung gezogen wurde.

3) Wurden die Nachbilder geprüft und zwar unter Vorlage von farbigen Papieren; als Farben wurden benutzt: Carmin, Rosa, Orange, Gelb, Hellgrün, Dunkelgrün, Blau. Das farbige Papier wurde den bekannten Heidelberger Farbenbüchern entnommen.

4) Die in der Holmgren'schen Arbeit sich findende Farbentafel wurde vorgelegt, und das betreffende. Individuum nach der Aehnlichkeit resp. Uebereinstimmung der einzelnen Farben gefragt. Allerdings habe ich damit die Holmgren'sche Tafel zu einen Zweck benutzt, 
welchen ihr der Autor eigentlich nicht vindicirt hat und lege ich deshalb gerade dieser Probe auch keine sonderliche Bedeutung bei.

5) Die Stilling'schen Tafeln wurden vorgelegt.

6) Farbige Gläser wurden dem Farbenblinden vorgehalten und zwar einmal gegen künstliches und das andere Mal gegen das Tageslicht und er dann nach den betreffenden Farbennamen gefragt.

7) Wurde die spectroscopishe Untersuchung mit der grössten Sorgfalt vorgenommen und zwar in der Weise, dass das betreffende Individuum zuerst das volle Spectrum vorgelegt erhielt und angeben musste, wie viel und welche Farben es darin erblickte. Alsdann wurden Metallspectra, und zwar Natrium, Lithium and Thallium und wenn nöthig auch Indium vorgelegt und wiederum nach dem Namen gefragt. Doch begnügte ich mich mit den subjectiven Angaben des Untersuchten niemals, sondern liess eine jede von ihm im Spectrum wahrgenommene Farbe sofort durch die ihm identisch erscheinenden Wollen der Holmgren'schen Proben charakterisiren.*)

*) Magnus. Zur spectroscopischen Untersuchung Farbenblinder. Centralblatt für Augenheilkande. 1878. Bd. II. p. 80. Cohn hat in der diesjährigen Versammlung deutscher Ophthalmologen (Beilage zum Augustheft des „Centralblatt für praktische Augenheilkunde" 1878 , p. XXXV), eine Modification dieser meiner wollspectroscopischen Methode in der Weise angegeben: dass der Farbenblinde für jede der ihm vorgelegten Spectralfarben nicht blos eine, sondern mehrere ihm identisch erscheinende Wollbündel heraussuchen solle. Ich muss in Abrede stellen, dass dieser Vorschlag Cohn's eine Modification meiner Methode enthält. Ich habe niemals gerathen, für die betreffende Spectralfarbe nur eine einzige pseudoidentische Wollprobe heranssuchen zn lassen, wie dies Cohn zu glauben scheint; vielmehr habe ich für jede einzelne Spectralfarbe immer sämmtliche dem Farbenblinden als gieich oder ahnlich erscheinende Wollproben herauslegen lassen. Diẹ von Cohn in Vorschlag gebrachte Modification meiner Methode anterscheidet sich also von der Art und Weise, wie ich dieselbe stets geubt habe und noch übe, ganz und gar nicht. 
Ich halte diese Art und Weise, die Spectroscopie mit der Holmgren'schen Methode zu verbinden, für höchst wichtig und für eine zuverlässige und erschöpfende spectroscopische Untersuchung gradezu für unentbehrlich. Uebrigens möchte ich hierbei gleich bemerken: dass sich diese meine Spectro-Wollmethode im Princip von der Holmgren'schen Methode in Nichts unterscheidet und ihre praktische Bedeutung lediglich in dem Umstande zu suchen ist, dass sie dem Untersucher es möglich macht, von den subjectiven Angaben des Untersuchten völlig abzusehen.

8) Die Aufnahme des Gesichtsfeldes, sowohl für Weiss, als auch für Roth, Blau und Grün lag zwar auch in meinem Plan, doch liess sich dieselbe nicht mit Consequenz durchfuhren. Denn da unser Untersuchungsmaterial nur aus Schülern, also aus jüngeren Individuen bestand, so wurden derartige Prüfungen durch die Unruhe und Unaufmerksamkeit der Untersuchten häufig genug so erschwert und darum so zeitraubend, dass ich schliesslich auf eine allgemeine Durchführung der Perimetrie verzichtete und dieselbe immer nur bei einigen wenigen Schülern in Anwendung zog, welche sich dazu als besonders geeignet zeigten. Die Aufnahme der Gesichtsfelder führte ich theils mit dem Förster'schen, theils mit dem Badal'schen Perimeter aus.*)

9) Es wurde genau nach den Erblichkeitsverhältnissen bei einem jeden Farbenblinden geforscht. Allerdings wurden diese Fragen oft genug vergeblich gethan und bei den Schülern der niederen Schulen fast niemals eine befriedigende Antwort erzielt; dafür erhielt ich aber von den Angehörigen der besseren Stände wiederholentlich

*) Da aber meine perimetrischen Untersuchungen keinerlei neue Gesichtspunkte zu Tage gefördert haben, werde ich grade diesem Capitel keine weitere Aufmerksamkeit zuwenden, um so mehr, da in dem vortreffichen Buch von Holmgren bereits die Perimetrie der Farbenblindheit genügend behandelt worden ist. 
sehr werthvolle Mittheilungen, welche grade diesen wichtigen Punkt vielleicht nicht unwesentlich fördern könnten.

10) Sowohl der Zustand der Sehschärfe, wie auch der der Refraction wurden bei einem jeden Farbenblinden genau festgestellt.

11) Die Farbe der Haare und der Iris wurde jedesmal notirt.

12) Es wurde nachgeforscht, ob die Eltern des farbenblinden Individuum's in irgend einem verwandtschaftlichen Verhältniss $z u$ einander stünden.

13) Gewisse Fälle von Farbenblindheit und speciell diejenigen, welche nur im Erkennen zarter Uebergangstöne eine Schwierigkeit empfanden, sich dagegen den ausgesprochenen, gesättigten Schattirungen gegenüber sicher zeigten, untersuchte ich noch in der Art, dass ich ihnen ein Sortiment ganz heller Seidenproben vorlegte und nach den Namen derselben fragte.

14) Es wurde nachgeforscht, ob der Farbenblinde hinsichtlich seines musikalischen Gehörs irgendwelche Abnormitäten an sich beobachtet habe.

15) Eine Untersuchung mit dem Augenspiegel wurde zum Schluss der gesammten Prüfung noch vorgenommen.

Da dieses ziemlich umfangreiche Untersuchungsprogramm, sollte es in allen seinen Nummern in verlässlicher und befriedigender Weise durchgeführt werden, stets eine längere Zeit in Anspruch nahm und eine stetige und ungeschwächte Aufmerksamkeit Seitens des Untersuchten verlangte, so führte ich die Prüfung des Einzelnen gar nicht selten in verschiedenen Zwischenräumen aus. Und zwar that ich dies immer dann, sobald ich bemerkte, dass der Farbenblinde ermüdete und in der Aufmerksamkeit nachliess.

Ein kurzer Blick auf den soeben charakterisirten Untersuchungsplan wird zeigen, dass in demselben sowohl diejenigen Methoden, welche an die subjectiven Angaben 
des Farbenblinden anknüpfen, berücksichtigt wurden, als auch diejenigen Platz gefunden haben, welche bestrebt sind: von den subjectiven Angaben so viel wie möglich abzusehen und nar objective Anhaltspunkte zu gewinnen.

Für eine endgültige und entscheidende kritische Beleuchtung der verschiedenen Untersuchungsweisen, wie wir sie im folgenden Paragraphen versuchen wollen, musste eine derartige gleichmässige und unpartheiische Berücksichtigung aller Methoden durchaus gefordert werden und aus diesem Grunde habe ich mich derselben auch unterzogen. Demjenigen, der eine eingehende Prüfung der verschiedenen Methoden und eine wissenschaftliche Durchforschung jedes einzelnen Falles von Farbenblindheit beabsichtigt, ist der Gebrauch des von Cohn der diesjährigen Ophthalmologenversammlung vorgelegten Fragebogens, der sich übrigens noch bedeutend erweitern und vervollständigen liesse, za empfehlen. Handelt es sich aber um Untersuchungen zu praktischen Zwecken, wie z. B. um Untersuchung eines Eisenbahnpersonals, so genügt es völlig, sich auf die Holmgrensche Methode zu beschränken und den Fragebogen bei Seite zu schieben.

§ 2. Kritik der verschiedenen Methoden.

Eine Kritik der verschiedenen, zur Untersuchung des Farbensinnes und speciell zur Entdeckung der Farbenblindheit in Vorschlag gebrachten Methoden wird sich dann in gedrängter Kürze geben lassen, wenn man von der charakteristischen Skizzirung ausgeht, welche $\mathrm{Helm}$ holt $z^{*}$ ) von einer solchen entworfen hat. Wenn ich nun auch voraussetzen darf, dass ein jeder meiner Leser diese von Helmholtz gebotene Schilderung kennen wird, so sei es mir doch gestattet, dieselbe hier an die

*) Helmboltz, Handbuch der physiologischen Optik. Leipzig 1867. p. 299.

v. Graefe's Arehiv fur Ophthalmologie, XXIV. 4. 
Spitze dieses Abschnittes zu setzen. Denn grade sie überhebt uns der Mühe, eine grosse Anzahl von Methoden kritisch $z$ u beleuchten und gestattet uns, unsere kritische Besprechung im Wesentlichen nur auf zwei Methoden, nämlich die von Stilling und Holmgren, zu beschränken. Die fragliche Stelle lautet: „Was die Untersuchung Farbenblinder betrifft, so wird durch Fragen, wie sie diese oder jene Farbe nennen, natürlich nur ausserordentlich wenig ermittelt werden, denn die Farben. blinden befinden sich in der Lage, das System von Namen, welches für die Empfindungen des normalen Auges zu. recht gemacht ist, auf ihre Empfindungen anwenden zu müssen, für die es nicht passt. Es passt nicht nur nicht, weil es zu viele Namen für Farbertöne enthält, sondern in der Reihe der Spectralfarben bezeichnen wir Unterschiede als solehe des Farbentons, die für die Farbenblinden nur Unterschiede der Sättigung oder Lichtstärke sind. Ob das, was sie Gelb oder Blau nennen, unserm Gelb oder Blau entspricht, ist mehr als zweifelhaft."

Indem wir nun unter Hinweis auf diese Darstellung, welche durch meine praktischen Erfahrungen vollständig bestätigt worden ist, summarisch alle diejenigen Methoden als unzulänglich bezeichnen, welche mit den subjectiven Aeusserungen des Farbenblinden über Natur und Namen der Farben in irgend einer Weise rechnen, und eine wirkliche Verlässlichkeit derartiger Methoden nur dann zugeben können, wenn sie ihrem Verfahren eine objective Controle zufugen, in ähnlicher Weise wie ich die Spectroscopie mil der Holmgren'schen Methode verbunden habe, wollen wir uns alsbald zur kritischen Betrachtung der beiden Methoden wenden, welche augenblicklich ohne Appell an die subjectiven Angaben des Untersuchten nux auf rein objectivem Wege ein Urtheil über den Farbensinn zu gewinnen streben, nämlich zu der Stilling'schen und Holmgren'schen Methode. 
Die Stilling'sche Methode*), die mittelst farbiger Lesetafeln die Farbenempfindung prüft, muss vom theoretischen Standpunkt aus gewiss als eine berechtigte angesehen werden. Wenn der Farbenblinde gewisse Farben als identisch bezeichnet, so ist es ja selbstverständlich, dass er Buchstaben und Figuren, welche aus diesen pseudo-isochromatischen Schattirungen zusammengesetzt sind, nicht als solche erkennen kann. Er wird somit auf derartigen Tafeln keinen Buchstaben lesen, während der Normalsichtige dies sehr wohl im Stande sein wird. Es muss demnach sehr leicht gelingen, für jeden einzelnen Farbenblinden aus den von ihm für identisch erachteten Farben pseudo-ioschromatische Tafeln zu construiren. Man braucht blos aus den als gleich bezeichneten Holmgren'schen Wollenproben eine beliebige Figur oder einen Buchstaben sticken lassen, wie dies z. B. Cohn**) versucht hat, und man hat alsbald eine pseudo isochromatische Tafel. Die Frage ist alsdann nur die, besitzen derartige Tafeln nun auch wirklich eine so ausgedehnte und allgemeine Gültigkeit, dass sie für einen jeden einzelnen Fall von Farbenblindheit sich bewähren, oder tragen sie nicht doch einen gewissen individuellen Charakter an sich, welcher ihre allgemeine Brauchbarkeit illusorisch machen, oder sie doch wenigstens beschränken könnte? Wir werden auf diese Frage gewiss dann am Besten zu antworten im Stande sein,

*) Stilling, Beiträge zur Lehre von den Farben. empfindungen, Beilageheft zu den klin. Monatsblattern für Augenheilkunde, 1877. - Stilling, die Prüfung des Farbensinnes beim Eisenbahn- und Marinepersonal. Cassel 1877. Stilling, Tafeln zur Bestimmung der Blau- und Gelbblindheit. Cassel, 1877.

**) Cohn, Gestickte Buchstaben zar Diagnose der Farbenblindheit. Centralblatt für praktische Augenheilkunde. 1878. p. 77 . 
wenn wir die einzelnen Stilling'schen Tafeln einer gründlichen praktischen Prüfung unterziehen und nur auf Grund derartig gewonnener praktischer Erfahrungen über die Brauchbarkeit ihres theoretischen Princips uns ein Urtheil erlauben. Folgendes sind nun die Resultate, welche ich mit Stilling's Tafeln erzielt habe.

Von 79 Farbenblinden, welche ich mit den erforderlichen Vorsichtsmassregeln, als da sind Vermeiden der Reflexe, Sorge für gutes Licht u. s. w. mit den fraglichen Tafeln untersucht habe, vermochten 24 keine der zur Untersuchung der Roth-Grünblindheit bestimmten Tafeln zu entziffern, während der Rest von 55 dies bei einer oder mehreren Tafeln im Stande war; und zwar stellten sich die Verhältnisse bei diesen 55 wie folgt: 36 lasen die roth-grüne Tafel sehr gut, 8 waren dies dagegen nur unter grosser Anstrengung und nachdem man sie darauf aufmerksam gemacht hatte, im Stande. Die rothbraune Tafel wurde von 7 Farbenblinden sofort entziffert; 14 erkannten sie nur mühsam und langsam. 23 Farbenblinde konnten weder die grün-rothe noch auch die rothbraune Tafel lesen, erkannten dagegen die Tafel mit dem grünen Kreuz sofort. 2 Blaublinde lasen die blau-gelbe Tafel. Im Allgemeinen habe ich also gefunden, dass die Stilling'sche Kreuztafel am leichtesten von Farbenblinden erkannt wird, dass alsdann die roth-grüne Schrifttafel am Besten entziffert wird, während die roth-braune Lesetafel die grössten Schwierigkeiten bereitet.

Wenn man vielleicht doch noch vermuthen könnte, dass diese meine Angaben über die Brauchbarkeit der Stilling'schen Tafeln etwa an meinem persönlichen Ungeschick liegen könnten, so wird diese Annahme alsbald hinfällig, wenn man hört, dass andere Untersucher genau dienämlichen Erfolge erzielt haben. So hat P flü ge $\mathrm{r}^{*}$ )

*) Bericht des Centralblattes für prakt. Augenheilkunde. Beilage zum Augustheft, p. XXXVIII. 
auf der diesjährigen Ophthalmologenversammlung zu Heidelberg die gleichen Angaben über die Unbrauchbarkeit der Stilling ${ }^{*}$ schen Tafeln gemacht und ist in seinen bezüglichen Mittheilungen von $\mathrm{Cohn}{ }^{*}$ ) völlig bestätigt worden. Wenn also drei Untersucher ganz unabhängig von einander zu dem nämlichen ungünstigen Urtheil über den praktischen Werth der Stilling'schen Tafeln gelangen, so wird man wohl zu der Annahme gedrängt werden, dass die Stilling'schen Tafeln in ihrer jetzigen Form zu einer verlässlichen Untersuchung auf Farbenblindheit nicht zu gebrauchen sind und keineswegs die Concurrenz mit anderen Verfahren auszuhalten vermögen. Es wird nun wohl gestattet sein, dem Grunde uachzuforschen, aus welchem die theoretisch durchaus richtige Stilling'sche Methode sich praktisch so wenig zu bewähren vermag. In erster Linie möchte ich nun hier die Vermuthung aussprechen, dass die Empfindung sogenannter pseudo-isochromatischer Nuancen nicht durchweg bei allen Farbenblinden genau dieselbe zu sein scheint, sondern vielmehr auch hier gewisse individuelle Schwankungen massgebend sein dürften. Wie bei der Beurtheilung und Empfindung der verschiedenen Farben nicht alle normalsichtigen Augen sich genau in derselben Weise verhalten, sondern hierbei zahlreiche individuelle Eigenthümlichkeiten zur Bethätigung gelangen, so könnten ähnliche Verhältnisse wohl doch auch bei Farbenblinden massgebend sein, welche deren Urtheil über isochrome Schattirungen individualisiren. Und an dieser Vorstellung möchte ich im Hinblick auf die zahlreichen Intensitätsgrade der Farbenblindheit um so mehr festhalten; besonders die vielfachen Abstufungen des herabgesetzten Farbensinnes zeigen so bäufig gewisse individuelle Eigenthümlichkeiten ihrer Farbenperception, dass ich mich vor

*) Ebendaselbst, p. XXXIII. 
der Hand nicht zu der Vorstellung zu entschliessen vermag: es könue mit einigen wenigen Tafeln allen diesen zahlreichen individuellen Empfindungsvorstellungen Rechnung getragen werden.

Inwieweit diese meine vermuthungsweise geäusserte Annahme sich in der Zukunft bewähren und ob sie durch die neue Folge*) der Stilling'schen Tafeln widerlegt werden wird, was ich im Interesse derselben ja wünschen möchte, bleibt auzuwarten; doch habe ich bereits auch schon gegen diese neuen Tafeln erhebliche praktische Bedenken auszusprechen. Der erste Fall, welchen ich mit diesen neuen Tafeln untersuchte, stellte die Brauchbarkeit derselben für Massenuntersuchungen alsbald wieder in Zweifel. Das betreffende Individuum war bereits als farbenblind erkannt und mit Hülfe verschiedener Methoden als total grünblind nachgewiesen worden. Es hätte nun nach Stilling's Angabe keine Tafel lesen dürfen und anfangs schien diese Behauptung Stilling's sich auch zu bestätigen; mein Farbenblinder: vermochte keine uinzige Tafel $z u$ entziffern. Als ich ihm nun aber sagte, dass auf dieser Tafel ein $L$, auf jener ein B, auf der dritten endlich ein $O$ u. s. w. zu finden seien, begann derselbe jede einzelne Tafel ganz richtig zu zeigen und mit dem Finger dem betreffenden Buchstaben auf jeder Tafel nachzufahren. Es steht also gleich der erste von mir mit den neuen Tafeln untersuchte Fall mit den Stilling'schen Angaben in Widerspruch; denn das betreffende Individuum war ohne jeden Zweifel vollständig grünblind und bätte also gar keine Tafel lesen sollen, war aber doch im Stande, jedem einzelnen Buchstaben mit dem Finger nachzufahren und so die Tafeln zu entziffern. Natürlich kann es mir nicht in

*) Stilling, die Prûfung des Farbensinnes beim Eisen bahn- uud Marinepersonal. Neue Folge. Erste Lieferung. Tafeln zur Bestimmung der Roth-Grünblindheit. Cassel, 1878. 
den Sinn kommen, auf Grund dieser einzigen Erfahrung diese neue Tafeln für ganz ebenso unbrauchbar zu erklären, wie die frühern, doch möehte ich bei wichtigen Massenuntersuchungen, wie z. B. bei Prüfung von Eisen. bahnbeamten, mich auf eine ausschliessliche Untersuchung mit diesen neuen Tafeln auch nicht mehr verlassen. Meine erste Probe mit denselben scheint mir eine gewisse Vorsicht zu gebieten, die gewiss grade dann nicht ausser Acht gelassen werden darf, wenn es sich um praktisch so wichtige Fragen handelt, als wie um die Untersuchung eines Eisenbahnpersonals.

Die Holmgren'sche Methode, über deren Gebrauchsfähigkeit ich mich bereits an einer anderen Stelle*) höchst lobend ausgesprochen habe, kann im Wesentlichen als ein weiterer Ausbau und eine Vervollkommnung des bereits von Seebeck**) in Vorschlag gebrachten Verfahrens gelten. Ohne von dem Untersuchten eine subjective Angabe über Namen und Qualität der Farben zu verlangen, trachtet diese Methode darnach lediglich auf dem Wege des Vergleichs ein Urtheil über den Farben$\operatorname{sinn}$ zu gewinnen. Dadurch, dass das zu untersuchende Individuum genöthigt wird, zu einer bestimmten farbigen Wollenprobe aus einem grösseren Sortiment gefürbter Wollenbündel die ihm gleich und identisch erscheinenden Wollen herauszusuchen, vermag der Untersucher die Bethätigung des Farbensinnes bei einem jeden einzelnen Individunm in der objectivsten Weise zu prüfen. Es ist ja doch ganz klar, dass bei der grossen Auzahl farbiger Wollenproben, sowie bei der leicht beweglichen Anordnung des Untersuchungsmaterials das einzelne In-

*) Magnus, Neueres zur Thoorie und Praxis der Farbenblindheit. Deutsche medicinische Wochenschrift. 1878. No. 20.

**) Seebeck, Mangel an Farbensinn. Poggendor's Annalen. B.42. No. 10. Berlin, 1837. 
dividuum den vollsten und weitesten Spielraum bat in der Auswahl und in der Anordnung der pseudo-isochro. matischen Nüancen. Die individuelle Empfindungsweise, sowie das specielle Urtheil, welches jeder einzelne Farbenblinde über die pseudo-isochromatischen Schattirungen und Töne hat, sie können grade durch das Holmgr en'sche Verfahren zur freiesten und ungestörtesten Bethätigung gelangen. Bleibt es ja doch dem individuellen Belioben des Einzelnen vollkommen überlassen, alle die Töne, welche ihm als identisch mit der vorgelegten hellgrünen Wollprobe erscheinen, aus dem umfangreichen Wollsortiment herauszusnchen. Und eben, weil dies der Fall ist und der Subjectivität des Einzeinen vermöge der leicht beweglichen Handhabung und Anordnung des Untersuchungsmaterials der weiteste Spielraum gestattet ist, muss ein jeder Intensitätsgrad der Farbenblindheit bei Benutzung des Holmgren'schen Verfahrens zu Tage gefördert werden. Die leichtesten Fälle von herabgesetztem Farbensinn, so wie die ausgesprochenen Fälle totaler Farbenblindheit, sie alle werden in gleich sicherer Weise durch jene Methode entdeckt. Und grade die leicht bewegliche Anordnung des Untersuchungsmaterials, welche einen derartigen sicheren Nachweis aller Formen von Farbenblindheit gestattet, sie sichert dem Holmgren'schen Verfahren seine grosse Ueberlegenheit allen anderen Methoden gegenüber. Darum muss nach meiner Anschauung auch die Holmgren'sche Methode an Sicherheit und Präcision immer die Stilling'sche, und mag dieselbe noch so sehr verbessert werden, übertreffen. Denn während die letztere die individuellen Anschauungen des Farbenblinden über die pseudo-isochromatischen Schattirungen in eine unveränderliche und unnachgiebige Vorschrift hineinzupressen versucht, steht die Holmgren'sche Methode von einem derartigen Versuch ganz ab und überlässt es lediglich dem Belieben eines Jeden, 
seine Vorstellungen über das Isochromatische in directester Weise durch Zusammenstellung der farbigen Wollen darzulegen.

Uebrigens klingen die Urtheile über die Leistungsfähigkeit der Holmgren'schen Methode fast einstimmig höchst güustig und anerkennend; auch auf der diesjährigen Ophthalmologenversammlung erfreute sich dieses Verfahren grosser Anerkennung; Cohn, Michel und Pflüger*) rühmten die Gebrauchsfähigkeit jener Methode in hohem Grade, und ich kann dem von ihnen gespendeten Lob nur aus vollem Herzen zustimmen. Das Bedenken, welches von einzelnen Untersuchern, z. B. Michel geäussert wurde, dass die leichteren Formen eines herabgesetzten Farbensinnes sich durch Holmgren's Verfahren nicht nachweisen liessen, kann ich nicht theilen; vielmehr haben meine praktischen Erfahrungen, welche ich bei der Untersuchung von gegen 5500 Personen gesammelt habe, mich grade das Gegentheil gelehrt. Anch die geringsten Fälle von Farbenschwäche kommen bei richtiger Handhabung jener Methode unzweifelhaft zu Tage. So muss ich denn die Holmgren'sche Methode für die beste und sicherste unter allen bestehenden erklären and den Wunsch aussprechen: dass dieselbe gleichmässig in ganz Deutschland zur Untersuchung des Eisenbahnpersonals benutzt werden möge. Ich halte es im Interesse der Sicherheit der öffentlichen Verkehrswege für höchst wünschenswerth, dass wir für alle deutschen Bahnen eine gleichmässige Untersuchungsmethode erhalten und zwar die Holmgren'sche. Dass dieser mein Wunsch nicht aus einer einseitigen Ueberschätzung des Holmgren'schen Verfahrens hervorgeht, sondern vielmehr lediglich nur dem thatsächlichen Verhältniss Rechnung trägt, geht wohl daraus hervor, dass

*) a. a. O. p. XL 
auch bereits von anderen Seiten her ähnliche Wünsche laut werden. So schreibt mir z. B. Dr. Jeffries unter dem 19. September d. J. aus Boston wie folgt: „My own experience teaches me the great value of $\mathrm{Holm}$ gren's method over all others, and I wish it would be ordered by your Kaiser through out Deutschland."

Die Vorwürfe, welche Stilling in der nenen Folge seiner Tafeln dem Holmgren'schen Verfahren macht, vermag ich durch meine Erfahrungen nicht zu bestätigen, ja ich bin sogar in der Lage, einzelne derselben sofort berichtigen zu könuen. Wenn er z. B. meint: Farbenblinde vermöchten durch Uebung im Sortiren eine solche Sicherheit in der Ausübung des Holmgren'schen Verfahrens zu erlangen, dass sie im Stande wären, dem Untersucher ihren Mangel zu verbergen, so habe ich grade gegentheilige Erfahrungen gemacht. Mir sind wiederholt von Bahnärzten Beamte zugeschickt worden, welche im Verdacht standen farbenblind zu sein, die aber ihr Gebrechen in Abrede zu stellen suchten. Diese Beamten nun, die gewiss kein Mittel unversucht gelassen haben werden, um ihren Fehler zu verbergen, wurden 3 auch $4 \mathrm{Mal}$ und in einzelnen Fällen noch öfter mittelst des Holmgren'schen Verfahrens geprüft, aber trotz aller Uebung ihrerseits und trotzdem sie das Holmgren'sche Verfahren sowohl durch die von ihrem Bahnarzt angestellten, als auch durch die von mir wiederholten Untersuchungen gründlich kennen gelernt hatten, konnten sie mir doch niemals ihre Farbenblindheit verbergen. Uebrigens möchte ich fast glauben, dass Stilling die Holmgren'sche Methode gar nicht genau nach den Vorschriften ihres Autors ausgeführt hat; denn wenn er p. 7 sagt, Holmgren stelle die Diagnose hauptsächlich mit rosa Wolle, so ist dies gradezu unrichtig und beweist mir, dass Stilling die betreffende Methode doch nicht ganz genau kennt; denn grade die eigentliche Diagnose 
auf Farbenblindheit wird bei der ersten Untersuchung nach Holmgren nur mit hellgrüner Wolle gestellt und Purpur erst gebraucht, wenn es sich nach einmal gestellter Diagnose darum handelt, die Form der Farbenblindheit genauer zu bestimmen. $\mathrm{Zu}$ einem genaueren Eingehen auf die Kritik, welche Stilling an dem Holmgren'schen Verfahren geübt hat, kann ich mich aber nicht berufen fühlen und dürfte auch hierza nicht an dieser Stelle der Ort gegeben sein. Ich begnüge mich daher, nochmals zu constatiren, dass eine grosse Reihe verlässlicher und erfahrener Untersucher das Holmgren'sche Verfahren für das beste erklärt haben.

\$ 3. Ergebnisse der Untersuchungen.

Die Ergebnisse, welche ich bei meinen ausgedehnten Untersuchungen des Farbensinnes erzielt habe, scheinen mir nach den verschiedensten Seiten hin ein gewisses Interesse zu besitzen. Einmal wird die Statistik der physiologischen Farbenblindheit durch sie erweitert und vervollständigt; dann gewähren sie einen Einblick in die Gesetze, nach welchen sich die Farbenblindheit über die verschiedenen Kreise der Bevölkerung erstreckt und schliesslich bieten sie wohl auch ein gewisses Material dar, um die augenblicklich herrschenden Theorien der Farbenwabrnehmung kritisch zu erhärten. Doch möchte ich mich gerade über diesen letzteren Punkt nur mit einer gewissen Reserve äussern und denselben mehr andeuten, als wirklich ausführlich behandeln, indem ich die erschöpfende Erforsehung dieses Theils unseres Themas berufeneren Autoren uberlasse.

Im Ganzen habe ich 5489 Schüler und Schülerinnen untersucht und zwar waren darunter 3273 Knaben und 2216 Mädchen.

Unter den 2216 untersuchten Mädcben, von denen 1330 Christinnen und 886 Jüdinnen waren, wurde 
nur 1 farbenblindes Individuum gefunden und zwar eine totale farbenblinde Christin*).

Unter den 3273 untersuchten Knaben**). wurden 100 Farbenblinde gefunden and zwar vertheilten sich dieselben in folgender Weise: unter 2509 christlichen Schülern befanden sich 71 Farbenblinde, während unter 764 Juden 29 farbenblind waren. Von den 3273 untersuchten Schülern besuchten ferner 2002 Gymnasien und höhere Privatschulen und unter ihnen fanden sich 53 Farbenblinde. Volksschulen und zwar speciell Elementarund Mittelschulen besuchten 1055 meiner untersuchten Schüler und von ihnen erwiesen sich 46 als mehr oder minder farbenblind.**)

Es würden die gefundenen Zahlen also folgenden Procentsatz ergeben:

Allgemeine Verbreitung der Farbenblindheit in allen männlichen Bevölkerungsschichten . . = $3,27 \%$, Verbreitung der Farbenblindheit unter den

Christen . . . . . . . . . . $=2,83 \%$ Verbreitung der Farbenblindheit unter den Juden . . . . . . . . . . . . $=3,79 \%$, Verbreitung der Farbenblindheit in den besseren Ständen. . . . . . . . $=2,65 \%$,

*) Eine genauere Besprechung der einzelnen Ergebnisse werde ich, um nicht die Uebersichtlichkeit des $\$ 3 \mathrm{zu}$ beeinträchtigen, erst in $\$ 4$ versuchen.

**) Un dem Einwand zu entgehen, dass die Knaben der unteren Klassen geistig noch zu unreif seien, um verlässliche Resultate bei einer Prüfung ihres Farbensinnes zu geben, habe ich meine Untersuchungen auf den Gymnasien stets mit der Sexta abgeschlossen und auf den Elementarschulen sie nicht über die erste Abtheilung der zweiten Klasse ausgedehnt.

**) 216 Sctüler gehörten jüdischen Religionsschulen an. Die unter ihnen gefundenen Farbenblinden sind bereits bei Gelegenheit der Untersuchung der Schulanstalten, die sie besuchen, gezählt worden. Ein Farbenblinder der Religionsschule wurde aus anderen Gründen bei der Classificirung der Schüler nach dem Rang der von ihnen frequentirten Anstalten nicht mitgezählt. 
Verbreitung der Farbenblindheit in den unteren Ständen . . . . . . . . $=4,36 \%$.

Wir hätten somit also drei Thatsachen constatirt, nämlich:

1) dass die Farbenblindheit in den unteren Ständen verbreiteter und häufiger ist, als in den höheren Schichten der Bevölkerung.

2) dass die Juden eine grössere Neigung und Anlage zur Farbenblindheit haben, als die Christen.

3) dass das weibliche Geschlecht eine auffallend geringe Neigung zur Farbenblindheit hat.

Ferner habe ich bei 93 der von mir entdeckten Farbenblinden*) folgende Verschiedenheiten hinsichtlich der Färbung der Haare und A u gen gefunden: Schwarze, braune und dunkelblonde Haare hatten unter den 93 farbenblinden Individuen 48 , während 45 blonde Haare besassen. Rothhaarig war keiner meiner Farbenblinden. Braune, gelbbraune oder gelbgraue Augen hatten 28, während blaue und blaugraue Augen sich bei 65 fanden. Es scheint hier nach fast so, als ob die älteren Autoren**) mit ihrer Behauptung: die Farbenblindheit sei ofter bei blauer resp. grauer Färbung der Iris zu be. obachten, als bei dunkelfarbiger Regenbogenhaut, eine thatsächliche Berechtigung finden können. Seebeck***)

*) Ausser den in den Schulen gefundenen 101 Farbenblinden habe ich in meiner Privatpraxis in dem letzten halben Jahr noch 11 Farbenblinde untersucht; natürlich habe ich diese 11 in meinem vorliegenden Bericht auch berücksichtigt, wenn ich sie auch nicht habe bei der procentarischen Berechnung nennen oder mitzählen dürfen.

**) Jüngken. Die Lehre von den Augenkrankheiten, Berlin 1836, 2. Auflage, pag. 876. Chelius. Handbuch der Augenheilkunde. Stuttgart 1843. Bd. I. $\$ 560$, pag. 377. Himly. Die Krankheiten und Missbildungen des menschlichen Auges und deren Heilung. Berlin 1843. Theil 2, pag. 468.

**) a. a. 0., pag. 178. 
hat unter seinen 12 Farbenblinden 10 mit blauen oder grauen und nur 2 mit dunklen Augen gehabt; übrigens macht derselbe darauf aufmerksam, dass dies häufigere Vorkommen heller Augen bei den Farbenblinden möglicherweise auf das zahlreichere Vertretensein blauer und grawer Augen bei allen nordischen Vôlkern zurückznführen sei.

Die Refraction, sowie die Sehschärfe wurde bei 76 karbenblinden genau festgestellt, und dabei Folgendes gefunden: Hypermetropisch waren 49 , während 20 myo pisch und 4 emmetropisch sich erwiesen und 1 Anisometropie zeigte, indem sein linkes Auge Myopie $\frac{1}{12}$ und das rechte Auge Hypermetropie $\frac{1}{40}$ hatte. Die Höhe der Hypermetropie bewegte sich bei den Farbenblinden zwischen $\frac{1}{13}$ und $\frac{1}{60}$, während bei den Myopen die Höhe des Refractionsfehlers zwischen $\frac{1}{8}$ and $\frac{1}{30}$ schwankte. Ausserdem fanden sich noch zwei mit einem Astigmatismus irregularis in Folge von Hornhautlecken.

Die Sehschärfe war bei 72 meiner untersuchten Farbenblinden $=1$; die übrigen 4 hatten eine mehr oder minder herabgesetzte Sehschärfe und zwar zwei Myopen eine Sehschärfe $=\frac{20}{30}$, ein Astigmatiker $=\frac{20}{50}$ und der andere $=\frac{20}{70^{\circ}}$

Ausserdem war das eine der mit Astigmatismus irregularis behafteten Individuen einäugig und zwar hatte es das eine Auge in Folge einer Scarlatina verloren.

Ophthalmoskopisch hatte ich bei allen von mir untersuchten Farbenblinden keinen besonders auffalligen 
Befund zu verzeichnen. Der gesammte Hintergrund, die Papille, der Reflexkreis um die Macula u. s. w. zeigte sich mit der jugendlichen Individuen eigenthümlichen Schärfe und Klarheit.

Der hervorragende Einfluss, welchen die Erblichkeit auf die Fortpflanzung und Verbreitung der Farbenblindheit ausübt, zeigte sich bei meinen Untersuchungen wiederum auf's Dentlichste. Unter 95 Farbenblinden, bei denen ich die Familienverbältnisse hinsichtlich einer erblichen Anlage zur Farbenblindheit durchforsehte, gelang es mir bei $42 *$ ) eine solche nachzuweisen. Und zwar ergaben sich dabei folgende Verhältnisse: 5 Mal waren die Eltern der Farbblinden normalsichtig, dafür aber der Grossvater farbenblind und zwar gelang es mir in dreien dieser fünf Fälle mit Sicherheit nachzuweisen, dass der Vater der Mutter, also der Grossvater mütterlicherseits, farbenblind war**). Diese überaus interessante Thatsache, dass sich die Farbenblindheit sprungweise vererbt vom Grossvater auf dessen männliche Enkel und zwar von dem Grossvater mütterlicherseits, scheint eines der Hauptgesetze für die Vererbung der Farbenblindheit zu bilden***). Wenigstens ist diese Vererbungsart bereits

*) Uebrigens darf man aus den von mir angegebenen Zahlen duxchaus keinen Rückschluss auf die procentarischen Verhältnisse der Erblichkeit der Farbenblindheit ziehen. Höchstens kömnen gerade diese Ziffern einen annähernden Werth beanspruchen. Der Grund hierfur liegt in dem Umstand, dass eine Menge meiner farbenblinden Individuen keine A hnung davon hatten, ob Mitglieder ihrer Familie einen abnormen Farbensinn hatten oder nicht; auch mit Hülfe der Fltern liess sich häufig keinerlei Aufschluss exzielen. Besonders war dies in den unteren Volksschichten der Fall.

$\left.{ }^{*}\right) \mathrm{Ob}$ in den beiden anderen Fällen der Grossvater mütterlicher- oder väterlicherseits farbenblind war, konnte ich nicht bestimmt ermitteln.

***) Wenn unter meinen Farbenblinden sich dies Gesetz nur 3 Mal nachweisen liess, so darf man diesem Umstand weiter keine 
von früheren Autoren wiederholt beobachtet worden; so finden sich derartige Beobachtungen bei Milne, Whittloch, Nicholl, Butler*), Helling**), Seebeck**) u. A. Einzelne Beobachter haben bereits auch schon den Versuch gemacht, aus den früheren Angaben ein Erblichkeitsgesetz für die Farbenblindheit herzuleiten; so sagt z. B. Rütef) über diesen Punkt: „Die Krankheit ist erblich, und zwar erbt sie merkwürdiger Weise mehr durch die Frauen als durch die Männer fort; z. B. theilen die Grossväter mütterlicher Seits sie ihren männlichen Enkeln mit." Auch Szokalski † ) hält diese Art der Vererbung für die häufigste. In der neuesten Zeit sind für dieses Vererbungsgesetz wiederum höchst werthvolle Beiträge geliefert worden und zwar von Professor Hornertt+). Derselbe ist in Besitz von zwei Stammbäumen, deren einer bis in das siebenzehnte Jahrhundert zurückreicht, welche gerade diesen Vererbungstypus in

sonderliche Bedeutung beimessen. Gelang es ja überhaupt nur in 5 Fällen von 95 genan den Nachweis zu führen, dass ein Grossvater farbenblind war; in den ubrigen 90 Fällen fehlte eine dahin zielende verlässliche und sichere Angabe vollständig. Berücksichtigt man diesen Umstand, so wird man an der geringen Zahl von 3 Fällen, in denen dies wichtige Erblichkeitsgesetz sich zutreffend zeigte, weiter keinen Anstoss mehr nehmen.

*) Ueber die Angaben dieser drei englischen Autoren vergleiche man: Szokalski. Ueber die Empfindungen der Farben in physiologischer und pathologiseher Hinsicht. Giessen, 1842, \$ 32, pag. 107.

*) Helling. Praktisches Handbuch der Augenkrankheiten. nach alphabetischer Ordnung. Berlin, 1821. Bd. I., pag. 2.

***) a. a. O. Beobachtung, II., pag. 195.

†) Rüte. Lehrbuch der Ophthalmologie für Aerzte und Sta* dirende. Braunschweig, 1845, pag. 86.

†t) a. a. 0., pag. 106.

$++\dagger)$ Horner. Die Erblichkeit des Daltonismus. Mittheilungen aus der ophthalmologischen Klinik. Ein amtlicher Bericht über die Verwaltung des Medicinalwesens des Kantons Zürich vom Jahre 1876. 
höchst charakteristischer Weise darbieten. Horner bringt, gestützt auf diese seine Beobachtungen, jenen Erblichkeitstypus in folgendem Gesetz zum Ausdruck: „Der Daltonismus vererbt sich nach dem Rückfalltypus vom Grossvater auf Enkel." Eine höchst interessante Bestätigung dieses Gesetzes erhielt ich jüngst durch eine briefliche Mittheilung des Professors Dr. Valentin in Bern, welcher unter dem 5. November d. J. schreibt: "Ich kann mir natürlich in Betreff der Horner'schen Ansicht über Farbenblindheit kein Urtheil erlauben, allein ich kenne wenigstens einen mir nahe stehenden Fall, der vollkommen für sie spricht. Der frühere hiesige Professor der Poliklinik F. war farbenblind; seine Kinder aber sind es nicht. Er hatte 5 Töchter, die -sich sämmtlich verheirathet haben und deren Kinder wiederum, wenigstens so weit ich es verfolgen konute, zum grössten Theil an Farbenblindheit leiden."

Jeffries*) hat in seinem soeben erschienenen Werkchen die Erblichkeitsverhältnisse der Farbenblindheit zwar auch eingehend erörtert und durch einige höchst charakteristische Fälle erläutert, doch scheint ihm jenes Gesetz nicht näher bekannt gewesen zu sein. Werthvoll gerade für diesen Punkt sind unter seinen Mittheilungen hauptsächlich die Angaben von Dr. Hochecker**), in dessen mütterlicher Familie die Farbenblindheit sehr verbreitet ist. Auch ich habe unter meinen Farbenblinden sechs Mal mit Sicherheit nachweisen können, dass die Verwandten mütterlicherseits farbenblind waren und somit die Farbenblindheit aus der Familie der Mutter auf das betreffende Individuum vererbt worden war. In dreien dieser Fälle waren die Brüder der Mutter, also die Onkel mütterlicherseits, Farbenblinde;

*) Wir haben auf die Arbeit des Dr. Jeffries bereits vorhin aufmerksam gemacht und besonders seine umfassende Literaturangabe hervorgehoben.

**) Dieses Archiv XIX., 3., S. 36-37.

v. Graefe's Archiv für Ophthalmologie, XXIV. 4. 
in zwei Fällen hatten zwei Schwestern je einen farbenblinden Sohn, vou denen ich eben den einen zu untersuchen Gelegenheit hatte. Einen gleichen Fall bat übrigens auch Seebeck*) mitgetheilt. In dem sechsten meiner Eälle hatten zwei Cousinen - Töchter zweier Schwestern - je einen farbenblinden Sohn ${ }^{* *}$ ).

Ich glaube demnach also, dass es kein voreiliger Schluss ist, wenn man annimmt, dass der Farbenblinde seinen Fehler sehr bäufig aus der Familie seiner Mutter ererbt und zwar in der Weise, dass seine Mutter einen normalen Farbensinn besitzt und immer nur ihre männlichen, nicht aber ihre weiblichen Nachkommen mit diesen Fehler ihrer Familie erblich belastet.

Natürlich schliesst der soeben geschilderte Erblichkeitstypus nicht unbedingt die Möglichkeit aus, dass auch von Seiten eines farbenblinden Vaters eine Vererbung der Farbenblindheit direct âf seine söhne erfolgen könne.

Derartige Fälle sind auch sicher beobachtet worden; so theilt $\mathrm{Scott} * * *$ ) einen solchen mit, ebenso Seebeck t) und ich habe davon vier gefunden.

Bei einer so ausgeprägten erblichen Uebertragung der Farbenblindheit ist es natürlich weiter nicht auffallend, wenn gewisse Familien eine ganz besondere Belastung mit diesen Gebrechen aufauweisen haben. So

*) a. a. 0., Beobachtung IX., pag. 211.

**) Derartige Beobachtungen liessen sich gewiss noch öfters machen; ich selbst habe von meinen Farbenblinden wiederholt die Angabe erhalten, der oder jener ihrer Vettern oder Onkel sei farbenblind, ohne dass sie im Stande waren, die Familienverhältnisse ganz genau darzulegen. Dies war im Ganzen vier Mal der Fall. Auch in der Literatur würden sich noch eine Menge Angaben über die Erblichkeitsverbältnisse bei der Farbenblindheit finden lassen, doch müssen wir auf eine eingehendere Mittheilung dieser Bemerkungen hier Verzicht leisten und uns mit einzelnen, besonders charakieristischen genügen lassen.

***) Szokalsky, pag. 107.

†) a. a. 0. pag. 180 u. 188. 
theilt Jüngken*) eine seiner Beobachtungen mit, nüch der in einer Familie durch drei Generationen hindurch sich eine Vererbung der Farbenblindheit mit Sicherheit constatiren liess und in der Familie des Dr. Pliny Earle ${ }^{* *}$ ) gelang dieser Nachweis sogar durch fünf Generationen. Aehnlich lauten ja übrigens auch die Beobachtungen Horner's und verschiedener anderer Autoren. Demgemäss kann es auch weiter nicht auffallend sein, wenn unter den Mitgliedern einer Generation eine erhebliche Verbreitung der Farbenblindheit existirt; so habe ich eine Breslauer Familie kennen gelernt, in welcher unter 5 Kindern, 4 Knaben und 1 Mädchen, sich 4 Farbenblinde fanden, und zwar waren alle 4 Knaben farbenblind, während dagegen das Mädchen einen ganz normalen Farbensinn hatte. Ausser diesem Fall habe ich noch zehn Mal die Beobachtung gemacht, dass zwei oder drei Brüder farbenblind waren.

In dem einen dieser Fälle waren drei und in dem andern zwei Brüder und zugleich auch der Vater farbenblind.

$\mathrm{Ob}$ eine Verwandtschaft der Eltern, auch wenn diese selbst nicht farbenblind sind, eine Anlage zur Farbenblindheit bedingt, darüber vermag ich keinerlei Aufschlüsse zu geben; nur so viel wage ich über diesen Punkt zu sagen, dass ich unter 94 Farbenblinden, welche ich darauf hin examinirte, nur sechs Mal erfuhr: Vater und Mutter seien Verwandte und zwar stets Cousin und Cousine. Natürlich sind diese Zahlen viel zu gering, um aus ihnen irgend einen Sehluss ziehen zu dürfen und muss ich deshalb diese Frage vor der Hand noch offen lassen.

Desgleichen vermag ich auch für die Frage, ob bei defectem Farbensinn auch Störungen im Gebiet des Nervus acusticus häufig zur Beobachtung gelangen und ob somit also ein gewisses Wechselverhältniss zwischen Gesichts- und Gehörsinn anzunehmen sei, keinerlei

*) a. a. 0., pag. 876 .

*) Jeffries a. a. 0., pag. 27. 
entscheidende Momente beizubringen. Viele meiner Farbenblinden schienen ein ganz gutes musikalisches Gehör gehabt zu haben und gaben an, die verschiedensten Instrumente zu spielen; ja Einer von ihnen wollte sich sogar völlig der Musik widmen. Doch glaube ich, dass gegenwärtig die betreffende Frage überhaupt noch gar nicht spruchreif ist. So lange man noch keine sichere Methode besitzt, um die Functionsfäbigkeit des Ohres nach allen Seiten hin zu untersuchen und man die musikalische Anlage des Ohres, das sogenannte musikalische Gehör, nicht in ähnlich erschöpfender Weise zu prüfen vermag, wie man dies bei dem Farbensinn im Stande ist, so lange darf man nicht daran denken, die betreffende Frage wirklich entgültig lösen zu wollen.

\section{\$ 4. Kritische Beleuchtung der gefundenen Thatsachen.}

Von den durch meine Untersuchung za Tage geförderten Thatsachen sind drei ganz besonders geeignet, unser Interesse $\mathrm{zu}$ erregen und uns zu einer genaueren kritischen Prüfung zu veranlassen; es sind dies die dreiGesetze, welche sich für die Verbreitung der Farbenblindheit ergeben haben und welche lauteten:

1) Das weibliche Geschlecht hat nur eine äusserst geringe Anlage zur Farbenblindheit.

2) Die Farbenblindheit ist in den unteren Ständen verbreiteter als in den höheren Schichten der Bevölkerung.

3) Die Juden haben eine grössere Neigung und Anlage zur Farbenblindheit als die Christen.

Bevor wir uns zu einer speciellen kritischen Beleuchtung dieser drei Thatsachen wenden, sei es uns gestattet, einige allgemeine Bemerkungen über die wissenschaftliche Bedeutung derselben vorauszuschicken. Das erste, den Unterschied zwischen dem Farbensinn des männlichen und weiblichen Geschlechtes ausdrückende 
Gesetz ist ein bereits früher gekanntes und hat dasselbe durch meine Untersuchungen nur wieder von Neuem seine Bestätigung gefunden. Dagegen sind das zweite und dritte Gesetz in allgemeinerem Umfang bisher noch nicht gültig gewesen und will ich eine derartige allgemeine Bedeutung denselben auch jetzt noch nicht auf Grund meiner Untersuchungen beilegen. Jene beiden Thesen sollen vor der Hand nichts Anderes ausdrücken, als das Verhältniss, welches hinsichtlich der procentarischen Verbreitung der Farbenblindheit unter den' von mir in Breslau untersuchten 5489 Individuen als herrschend sich ergeben hat, Für die von mir geprüften Schulkinder muss es als wahrscheinlich gelten, dass sowohl zwischen den höheren und niederen Bevölkerungsschichten, als auch zwischen Christen und Juden ein nachweisbarer Unterschied bezüglich der procentarischen Verbreitung der Farbenblindheit herrscht. Ob diese Thatsachen nun aber lediglich einen localen Charakter an sich tragen, oder einen allgemeineren Werth und eine verbreitetere Geltung beanspruchen dürfen, dies wird durch die verschiedensten au anderen Orten und unter auderen Verhältnissen vorgenommenen Untersuchungen entschieden werden müssen. Es haben also die beiden letzten unserer drei Gesetze vor der Hand noch einen relativen Werth, und indem ich diesen Standpunkt festhalte, wende ich mich nunmehr zu der kritischen Besprechung eines jeden derselben.

1) Das weibliche Geschlecht hat eineäusserst geringe Anlage zur Farbenblindheit.

Die Thatsache, dass das Weib eine viel geringere Aulage zur Farbenblindheit besitzt als der Mann, dass sein Farbensinn also, wenn man so sagen darf, kräftiger und resistenter ist, dem weiblichen Organismus sich fester angeschlossen bat, als dem männlichen, ist eine schon längst gekannte. Bei den meisten älteren Autoren, welche sich mit diesem Gegenstand beschäftigt haben, 
findet man Bemerkungen, welche auf einen derartigen zwischen dem Farbensinn des männlichen und weiblichen Geschlechts herrschenden Unterschied hinzielen. Doch begnügten sich die älteren Forscher meist nur mit allgemeinen derartigen Angaben und unterliessen es, ihre Bemerkungen durch die Beigabe statistischen Materials zu vervollständigen und zu vertiefen. Die Untersucher, welche in der neueren Zeit dieser auffallenden Thatsache ihre Aufmerksamkeit zugewendet haben, haben dafür um so reíchlichere statistische Notizen geliefert und dürfte es vielleicht nicht ohne Interesse sein, in einer kurzen Zusammenstellung einige neuere einschlägige Untersuchungsresultate mitzutheilen:

\begin{tabular}{|c|c|c|c|c|}
\hline $\begin{array}{l}\text { Unter- } \\
\text { sucher. }\end{array}$ & $\begin{array}{c}\text { Or t } \\
\text { der } \\
\text { Untersuchung. }\end{array}$ & $\begin{array}{c}\mathrm{Zahl} \\
\text { der } \\
\text { Untersuchten: }\end{array}$ & $\begin{array}{c}Z \mathrm{Zahl} \\
\text { der } \\
\text { Farbenblinden }\end{array}$ & 莺 \\
\hline Dor*) & Berlin & 611 & 5 & 0,82 \\
\hline Hansen & Kopenhagen & 50 & 0 & 0 \\
\hline Jeffries ${ }^{* *}$ ) & Boston & 1025 & 1 & 0,09 \\
\hline Cohn $* * *)$ & Breslau & 1061 & 0 & 0 \\
\hline Magnus & Breslan & 2216 & 1 & 0,04 \\
\hline Holmgrent) & Upsala & 7119 & 19 & 0,26 \\
\hline \multirow[t]{2}{*}{ Daae + t) } & Kragerö & 208 & 5 & 2,40 \\
\hline & Summa & 12,290 & 31 & 0,25 \\
\hline
\end{tabular}

*) Dor. Ueber Farbenblindheit. Separatabdruck aus den Verhandlungen der Bern'schen naturforsch. Gesellschaft vom 20. Juli 1872, pag. 2 und 3 .

**) Jeffries. Relative frequency of color-blindness in males and females. Cambridge 1878. Separatabdruck aus: The Boston medical and surgical Journal. Juli 25. 1878. Dieser Arbeit ist auch die Mittheilung Hansen's entnommen. In meiner jüngst erschienenen Arbeit: Die Farbenblindheit, ist irrthümlich angegeben worden, dass Jeffries kein farbenblindes Mädchen gefunden habe, während ex eins entdeckt hat.

***) Cohn u. Magnus. Untersuchung von 5000 Schulkindern in Bezug auf Farbenblindheit. Centralblatt für praktische Augenheilkunde. 1878. Maiheft.

t) Holmgren. Om Färgblindheten i Sverige. Upsala. Läkareförenings Förhandlingar 1878.

t+) Daae. Ein Beitrag zur Statistik der Farben- 
Die Zahl 30 gilt übrigens nicht ausschliesslich nur für vollständig farbenblinde Frauen, sondern sie umfasst auch eine ganze Reihe von Fällen herabgesetzten Farbensinnes. Jedenfalls beweist sie aber in höchst schlagender Weise den auffälligen Unterschied, der zwischen der Beschaffenheit des männlichen und weiblichen Farbensinnes herrscht; der Procentsatz der Farbenblindheit beim männlichen Geschlecht betrug nach meinen Untersuchungen 3,27 und der des Weibes nur 0,25.

Sehen wir uns nach einer Erklärung für dies auffallende Gesetz um, so ist auch an einer solchen in der Literatur kein Mangel. Da wir aber an dieser Stelle nicht die Absicht haben können, eine ausfübrlichere historische Darstellung dieses Gegenstandes unseren Lesern vorzuführen, so wollen wir uns mit der Bemerkung abfinden, dass in unserem Jahrhundert hauptsächlich die auf dem Boden der Naturphilosophie entstandenen Erklärungen*) Beifall gefunden und eigentlich

blindheit. Centralblatt für prakt. Augenheilkunde 1878 , pag. 79. Der hohe Procentsatz, welchen dieser Untersucher bei den Frauen gefunden hat, erklärt sich lediglich dadurch, dass er die Grenzen des Begriffes der Farbenblindheit ziemlich weit steckt und besonders die ganz leichten Formen der Farbenblindheit, welche zwischen dieser und dem normalen Farbensinn liegen, in seine Statistik aufgenommen hat.

*) Für diejenigen meiner Leser, die in den Anschauungen früherer Perioden nicht bloss nutzlose Curiosa erblicken, sondern beachtenswerthe Merksteine des Entwickelungsganges, den unsere Wissenschaft genommen hat, erlaube ich mir an dieser Stelle die Erklärung zu citiren, welche eine ophthalmologische Autorität, wie Szokalski (a. a. O., pag. 113), allerdings bereits im Jahre 1842, für das uns hier beschäftigende Gesetz gegeben hat: „Das Weib, die Mutter der Menschheit, ist mehr als der Mann mit der Natur verbunden und in Uebereinstimmung mit der Welt; sie vereinigt in sich allein eine grosse und allgemeine Idee des menschlichen Geschlechtes: sie repräsentirt das universelle Princip. Der Mann, seiner physischen und moralischen Natur nach, als Culminationspunkt der Schöpfung, reisst sich von derselben los, isolirt sich von den ihn umgebènden Gegenständen und giebt uns somit eine richtige Idee von dem egoistischen Princip, welches in ihm vorherrscht. 
bis in die neuere Zeit hinein geherrscht haben und erst durch die Lehren, welche die moderne Naturwissenschaft predigt, völlig verdrängt worden sind. Gegenwärtig scheint man allgemein der Ansicht zu sein, dass die geringere Anlage zur Farbenblindheit beim weiblichen Geschlecht wesentlich als das Resultat einer besseren Erziehung des Farbensinnes aufgefasst werden müsse. Die frühzeitige und häufig wiederkehrende Beschäftigung mit bunten Farben, wie sie gerade dem weiblichen Geschlecht durch Handarbeiten mit farbigen Gegenständen, sowie durch die vielfarbige Kleidung dargeboten wird, soll ein fördersames und wichtiges Bildungsmittel des weiblichen Farbensinnes bilden*). Das einzelne weibliche Individuum kräftigt und bildet seinen Farbensinn auf diese Weise mehr oder weniger und indem nun diese, wenn auch nur unbedeutende Erhöhung des Farbensinnes bei dem einzelnen Individuum sich weiter vererbt, nimmt sie allmählig an Intensität und Umfang zu, bis eben schliesslich der weibliche Farbensinn dem männlichen in der Weise überlegen geworden ist, wie dies die Untersuchungen allgemein ergeben haben. Es sei uns gestattet, diese Anschauung durch ein ein-

Eben so sicher wie in ihm die intellectuellen Fähigkeiten entwickelt sind, eben so sind bei dem Weibe die Wahrnehmungsfunctionen vorherrschend; es ist also in der Vereinigung beider Geschlechter, dass wir die Idee der mensehlichen Vollkommenheit zu suchen haben. Diese Betrachtungen verfolgend, begreift man leicht, warum das Weib eine grössere und zartere Empfindlichkeit für die Farben besitzt. Die Entwickelung dieses Gefühls ist eines der stärksten Bande, um die Mutter der Menschheit mit der übrigen Schöpfung zu-vereinigen."

*) จ. Bezold. Die Farbenlehre im Hinblick auf Kunst and Kunstgew erbe. Brannschweig 1874, pag. 152 u. 153.

Lederer. Farbenblindheit und mangelhafter Farbensinn, mit Rücksicht auf den Signaldienst der Eisenbahne $n$ und der Marine. Wiener med. Wissensch.1878: Nr. 2-4.

Da a e, a. O. 0 . 
schlägiges Citat einer Autorität, wie Holmgren*) es auf dem Gebiet der Farbenphysiologie ist, zu erhärten; derselbe sagt: "Wenn Uebung Einfluss haben kann auf diesen Punkt (geringeres Forkommen der Farbenblindheit bei den Frauen), so wird nach unserer Ansicht nicht sowohl das einzelne Individuum geheilt, als viel. mehr das ganze Geschlecht und zwar in der Weise, dass die Uebung sich ganz unmerklich auch auf die kommenden Geschlechter erstreckt. Wir kennen zwar die Gesetze der Vererbung zu wenig, um uns über solche Muthmassungen zu äussern, doch wissen wir mit Bestimmtheit, dass gute und schlechte Eigenschaft sich vererben und unter letztere gehört die Farbenblindheit; und schliesslich glauben wir auch, dass Uebung eines Sinnes auf dem Wege der Erblichkeit befriedigende Erfolge erzielen kann, mag uns der Beweis dafür auch noch schwer fallen." Aehnlich klingt die Erklärung, welche Dr. Daae giebt und die lautet: "Wahrscheinlicher ist es mir, dass der schärfere Farbensinn, welchen das weibliche Geschlecht durch viele Generationen bei Handhabung farbiger Gegenstände erworben und entwickelt hat, wesentlich sexuell ist oder nur bei weiblichen Generationen sich vererbt."

Die soeben vorgetragene Erklärung stützt sich also im Wesentlichen auf zwei Momente, auf wiederholte Uebung und auf Vererbung und schliesst sich damit den modernen Anschaungen auf das Innigste an. Sind wir nun aber von der Wirksamkeit dieser beiden Factoren äberzeugt und nehmen wir an, dass lediglich durch ihre Thätigkeit der weibliche Farbensinn seine gegenwärtige Leistungsfähigkeit erlangt hat, so sind wir nothwendigerweise zu dem Schluss gezwungen: dass dieselben beiden Factoren, kämen sie beim männlichen Geschlecht zur

*) a. a. 0., pag. 58 . 
Geltung, auch hier einen ähnlichen Effect erzielen müssten. Es müsste demnach also auch der männliche Farbensinn bei wiederholter, schon frühzeitig beginnender Uebung allmählig auf dem Wege der Vererbung gekräftigt und damit seine Neigung zur Farbenblindheit beschränkt werden kömen. Dieser Schluss ist gewiss kein willkürlicher, einer allzu reichen Phantasie entsprungener, sondern nichts weiter als wie die unmittelbare Consequenz jener für den Zustand des weiblichen Farbensinnes gegebenen Erklärung. Und weil er dies ist, so halten wir es für geboten, ihn in seinen praktischen Folgen näher in's Auge zu fassen und ihn zum Ausgangspunkt einer gegen die Verbreitung der Farbenblindheit sich richtenden hygieinischen Massregel zu machen. Und dies um so mehr, weil es ganz unzweifelhaft ist, dass gerade die Vererbung für den Umfang und die Leistungsfähigkeit des männlichen Farbensinnes von grösster Wichtigkeit ist. Haiten wir also an der Anschauung fest, dass der männliche Farbensinn genau so wie der des Weibes durch frühzeitige, systematische Uebung gekräftigt und diese individuelle Kräftigung allmählig auf dem Wege der Vererbung gleichfalls eine sexuelle Eigenthümlichkeit der Männer überhaupt werden könne, so wird es unsere Aufgabe sein: für eine derartige frühzeitig beginnende Uebung und Erziehung des Farbensinnes bei den Knaben zu sorgen. Die einzige Möglichkeit, eine solche systematische und methodisch geübte Erziehnng des Farbensinnes mit Erfolg ein- und durchzuführen, beruht in der obligatorischen Einführung derselben in allen Schulen, speciell in den Klassen, welche kleine Knaben zuerst besuchen. Gelingt es, eine dahin zielende ministerielle Verfügung zu erwirken, so ist anch zu hoffen: dass allmählig die Neigung zu der Farbenblindheit beim männlichen Geschlecht eingeschränkt werde, ähnlich wie die Neigung zur Farbenblindheit bei 
den Frauen durch frühzeitig beginnende Bethätigung des Farbensinnes in der wirksamsten Weise bekämpft wird.

Um nun in den Knabenschulen, speciell in den ersten Klassen der einzelnen Anstalten, welche von den Anfängern besucht werden, einen systematischen Unterricht des Farbensinnes zu ermöglichen, habe ich folgendes System entworfen.

Eine Karte, welche so eingerichtet ist, dass sie an einer gut beleuchteten Wand des Klassenzimmers aufgehängt werden kann, enthält in methodischer Anordnung die wichtigsten Farben, z. B. Braun, Purpur, Scharlach, Gelb, Grün, Blau, Violett, Schwarz. Eine jede dieser Farben ist in vier verschiedenen Nüancen auf der Tafel vorhanden, so dass sowohl die dunklen wie die bellen Schattirungen und Uebergangstöne einer jeden einzelnen Farbe sich finden. Der Lehrer beginnt bei den Anfängern, also den kleinsten Knaben, den Unterricht in der Weise, dass er die einzelnen Farben nennt und sich darauf von den Schülern die Namen wiederholen lässt. Ist dies geschehen, so kann der Lehrer über das Verhältniss, in welchem die einzelnen Schattirungen einer jeden Farbe zu einander stehen, noch Aufschlüsse geben und erklären, was Hell und Dunkel einer jeden Farbe sei u. s. w. Rathsam ist es, dass hierbei der Lehrer seine Unterweisung stets mit den mittleren, besonders scharf charakterisirten Farbentönen beginne; sie sind im Beginn für das kindliche Auge leichter zu fassen und zu verstehen, als wie die hellen und dunklen Schattirungen.

Ist auf diese Weise bei den Knaben eine gewisse, wenn auch bescheidene Kenntniss des Farbensystems er. zielt worden, so mag der Lehrer in seinem Unterricht weiter vorschreiten, zu der zweiten Abtheilung des gesammten Unterichtsplanes übergehen. In dieser zweiten Abtheilung benützt der Unterrichtende ausser der farbi- 
gen Tafel noch ein Kästchen Wollproben und zwar sollen die einzelnen Farbentöne, welche auf der Tafel dargestellt sind, in drei oder vier Wollbündeln vorhanden sein. Der Lehrer zeigt nun zuerst eine beliebige Farbe auf der Tafel und fordert dann den Schüler auf, diese betreffende Farbe durch das ihm identisch erscheinende Wollenbündel zu charakterisiren. Hat der Schüler diese Aufgabe richtig gelöst, so wänscht nun der Lehrer eine dunklere oder hellere Sehattirung des nämlichen Tones, der soeben mit Erfolg. aus den Wollproben herausgesucht worden ist, zu sehen. Hat sich der Schüler in diesen Aufgaben wiederholentlich geübt, so kann der Lehrer die Anforderungen höher stellen; er mag dann z. B. irgend einen farbigen Gegenstand, etwa eine Rose oder ein Veilchen u. s. w. nennen und verlangen, dass der Schüler die Farben dieses Gegenstandes durch eine Probe der farbigen Wollen charakterisire.

Befolgt man die von mir soeben geschilderte Methode, so glaube ich wohl, dass ohne eine besondere Belastung des wöchentlichen Stundenplans sich der Unterricht des Farbensinnes in den allgemeinen Unterricht einfügen lassen wird. Uebrigens ist der Wunsch: eine systematische Erziehung des Farbensinnes in den Schulen einzubürgern, durchaus kein neuer, vielmehr haben schon wiederholt Pädagogen derartige Vorschläge gemacht*) und in allerneuester Zeit ist anch von ärztlicher Seite eine Befürwortung derartiger Bestrebungen erfolgt, insofern Dr. Favre**) für eine allgemeine Einführung des

*) Augenblicklich liegen mir drei Farbentafeln für den Unterricht in der Schule vor; es sind dies die Tafeln von Band, Lehrer in Leiprig; Pateck, Schulrath in Prag und Hirrlinger, Maler in Stuttgart. Alle diese Tafeln leiden aber in erster Linie daran, dass sie den Zweck, welchen sie verfolgen, sowie die Resultate, die sie erzielen wollen und können, durchaus nicht in klarer Weise darlegen und entwickeln.

**) Daltonisme. Arch. génểr. 1878, pag. 371, Artikel 9. 
Farbensinnunterrichtes in den Schulen plaidirt. Allein alle dahin zielenden Vorschläge haben insofern gefehlt, als sie den Zweck und die erreichbaren Resultate einer systematischen Erziehung des Farbensinnes entweder im Dunkeln liessen, oder dieselben sogar völlig verkannten; so gilt dies besonders von Favre, welcher eine wirkliche Heilung des farbenblinden Individuum's durch den Unterricht zu erzielen hofft. Nun derartige Hoffnungen sind und bleiben illusorisch, da ein wirklich Farbenblinder niemals durch Uebung und Erziehung seines Farbensinnes sein physiologisches Gebrechen bessern oder gar beseitigen wird. Ein farbenblind Geborener bleibt, und mag er seinen Tarbensinn noch so fleissig üben, doch immer farbenblind; lernt er es wirklich die eine oder die andere Farbe zu unterscheiden, so empfindet er sie darum doch lange noch nicht in der Weise, wie der Normalsichtige. Er vermag die Farben niemals in Folge ihrer eigenthümlichen und charakteristischen Farbenerscheinung von einander zu unterscheiden und za trennen, sondern er kann dies nur, indem er seine Empfindlichkeit für die Lichtstärke der einzelnen Farben zu Hülfe ruft. Und da nun grade die Empfänglichkeit für Lichteindrücke bei den Farbenblinden eine höhere ist, als wie bei dem Normalsichtigen*), so kann er auch in der vermeintlichen Unter-

*) Ob die grössere Empfindlichkeit gegen Lichteffecte eine dem Farbenblinden angeborene physiologische Eigenthümlichkeit ist, will ich nicht entscheiden, doch möchte ich mich zu einer derartigen Anschauung nicht bekennen. Ich halte diese hohe Empfänglichkeit gegen zarte, für ein normalsichtiges Auge kanm merkbare Unterschiede in der Lichtstärke vielmehr für eine Uebungssache; dadurch, dass der Farbenblinde von Jugend auf darauf bingewiesen wird, an seiner Umgebung hauptsächlich auf die Lichteffecte zu achten, schärft er eben seinen Lichtsinn und macht ihn zartfühliger. Ich möchte dies Verhältniss vergleichen mit dem, in welchem das Tastgefühl beim Blinden steht. Hier erreicht dasselbe ja auch lediglich durch frühzeitig beginnende Uebung jenen staunenswerthen Umfang seiner Leistungsfähigkeit. 
scheidung der Farben eine gewisse Uebung erlangen. Doch darf man nie vergessen, dass diese Uebung immer nur eine künstlich anerlernte und höchst unsichere ist, welche mit einer wirklichen Kenntniss der Farben absolut vichts $z$ u thun hat; darum muss man auch Holmgren*) völlig beipflichten, wenn derselbe sagt: ,Il est toujours vicié, il n'a fait qu 'apprendre un artifice". Man darf somit sich nicht der Hoffnung hingeben: dass durcb eine systematische Erziehung des Farbensinnes das einzelne farbenblinde Individuum eine erhebliche Besserung erlangen werde, sondern man muss von vornherein den Effect der Farbensinnerziehung in einer allmäligen, sich über Generationen hin erstreckenden Kräftigung des Farbensinnes suchen. Unter strengster Wahrung dieses Standpunktes empfiehlt sich aber die Einführung einer systematischen Erziehung und Bildung des Farbensinnes in den Schulen sehr dringend. Das Experiment, welches die Natur uns an dem weiblichen Farbensinn gleichsam vorgemacht hat, muss za einer Nachahmung desselben beim männlichen Geschlecht unter allen Umständen auffordern.

Wenden wir ans nuumehr zu der kritischen Beleuchtung des zweiten Gesetzes, welches lautete:

Die Farbenblindheit ist in den unteren Stän. den verbreiteter, als in den höheren Schichten der Bevölkerung.

Halten wir an den Anschauungen, welche für die Erklärung des soeben erläuterten ersten Gesetzes benutzt worden sind, fest und verfolgen wir sie in ihren weiteren Consequenzen, so führen uns dieselben za der Annahme: dass in den unteren Bevölkerungsschichten der Farbensinn bei dem männlichen Geschlecht im Allgemeinen ein weniger ausgiebiger sein müsse, als in den höheren

*) a. a. $0 .$, p. 63 . 
Volksklassen. Denn die besseren Stände schenken der Bildung und Entwickelung des Farbensinns bei der männlichen Jugend entschieden eine grössere Aufmerksamkeit, als wie dies die unteren Volksklassen thun. Bunte Bilderbücher, Tuschkasten $u$. s. w. bilden in den Händen der höheren Bevölkerungsschichten angehörenden Knaben ein bekanntes Spielzeug und sie bilden gewiss einen, wenn anch nicht grade grossen Factor für Weckung und Ausbildung des Farbensinnes. Und grade dieser Factor fehlt in den unteren Volksschichten häufig so gut wie ganz. Darum liegt der Schluss nahe, dass die besseren Stände wohl in ihren männlichen Mitgliedern einen besseren Farbensinn und eine geringere Neigung zur Farbenblindheit haben könnten, als die niederen Klassen. Diese theoretische Speculation führte mich zuerst auf den Gedanken, bei meinen Untersuchungen das bezügliche Verhältniss genau zn verfolgen. Das Ergebniss meiner Forschung war nun, wie ich bereits in $\S 3$ angegeben habe, folgendes:

\begin{tabular}{c|c|c|c}
\hline $\begin{array}{c}\text { Character } \\
\text { der } \\
\text { Sehulen. }\end{array}$ & $\begin{array}{c}\text { Zahl } \\
\text { der Unter- } \\
\text { suchten. }\end{array}$ & $\begin{array}{c}\text { Zahl } \\
\text { der Farben- } \\
\text { blinden. }\end{array}$ & Procentsatz. \\
\hline $\begin{array}{c}\text { Gymnasien und höhere } \\
\text { Vorbereitungsschulen. }\end{array}$ & 2002 & 53 & 2,65 \\
$\begin{array}{c}\text { Mittel- und Elementar- } \\
\text { schulen . . *. }\end{array}$ & 1055 & 46 & 4,36
\end{tabular}

Hiernach wäre also für die von mir untersuchten Breslaner Anstalten zwischen höhexen und niederen Schulen ein Unterschied von etwa $2^{\circ}$ nachgewiesen. Aehnlich scheinen sich auch die Anstalten verhalten zu haben, welche $\operatorname{Coh}{ }^{*}$ ) untersucht hat; denn sie ergaben nach

*) a. a. O., p. XI. 
den Mittheilungen, die er auf der diesjährigen Ophthalmologenversammlung gemacht hat, folgendes Resultat:

\begin{tabular}{c|c|c|c}
\hline $\begin{array}{c}\text { Charakter } \\
\text { der } \\
\text { Schulen. }\end{array}$ & $\begin{array}{c}\text { Zahl } \\
\text { der Unter- } \\
\text { suchten. }\end{array}$ & $\begin{array}{c}\text { Zahl } \\
\text { der Farben- } \\
\text { blinden. }\end{array}$ & Procentsatz. \\
\hline $\begin{array}{c}\text { Gymnasien und höhere } \\
\text { Vorbereitungsschulen . }\end{array}$ & 1424 & 47 & 3,35 \\
$\begin{array}{c}\text { Mittel*)- und Elementar- } \\
\text { schulen . . . . - }\end{array}$ & 1005 & 48 & 4,8 \\
\hline
\end{tabular}

Wenn nun unsere Ziffern vor der Hand noch zu klein und hinsichtlich ihrer Höhe zu ungleich sind, um einen allgemeinen Rückschluss zu machen, und gegen eine derartige Auffassung habe ich mich ja Eingangs dieses Paragraphen ausdrücklich verwahrt, so sind sie doch jedenfalls geeignet, fürr unsere Breslauer Verhältnisse einen Unterschied in der procentarischen Verbreitung der der Farbenblindheit unter den verschiedenen Volksklassen wahrscheinlich zu machen. Wenn ich ein derartiges Gesetz für die Breslauer Bevölkerung auf Grund meiner und Cohn's Untersuchungen fixiren möchte, so kann ein solches Gesetz selbst auch für die Breslaner Verhältnisse natürlich immer nur eine allgemeine Geltung haben und darf nicht für jede einzelne kleine Schule als mass-

*) Man muss die Mittelschulen entschieden unter die Rubrik der von den unteren Volksklassen besuchten Sehulen bringen. Das Schülermaterial recrutirt sich grade in dièsen Anstalten im Wesentlichen und Hauptsächlichen aus den niederen Bevölkerungsschichten, wenn vielleicht auch aus den besser situirten Familien der unteren Volksklassen. Ich habe grade diesem Punkt bei den Untersuchungen meine besondere Aufmerksamkeit geschenkt und mir von den Directoren und Lehrern der von mir untersuchten Anstalten stets Aufschluss über die Beschaffenheit ihres Schülermaterials geben lassen. Ihre Mittheilungen lauteten stets so, dass ich die Mittelschnlen in die Rubrik der von den niederen Volksschichten frequentirten Anstalten zu. bringen mich genöthigt sah. 
gebend herangezogen werden. Die Vertheilung der Farbenblinden in den einzelnen Anstalten ist ja doch immerhin eine zufällige und man wird Volksschulen finden, die nur wenig Farbenblinde haben, während andere wieder um so mehr beherbergen. Ein derartiges Verhältniss ist eigentlich selbstverständlich und ich unterlasse es daher auch, eine specielle Uebersicht über die einzelnen von mir geprüften Schulen zu geben. Wenn aber $\mathrm{Cohn}^{*}$ ) meint: seine Untersuchungen hätten das umgekehrte Verhältniss wie die meinigen gegeben und sich dabei auf eine Elementarschule mit 257 Schülern stützt, so glaube ieh, dass diese Angabe für unsere Behauptung weiter nicht von Belang sein kann; überdies bestätigen grade die Ergebnisse Cohn's, wofern man nur die Mittelschulen mitzählt - und dies muss man unter allen Umständen - die grössere Verbreitung der Farbenblindheit unter den niederen Volkskreisen Breslau's genau in der nämlichen Weise, wie dies die meinigen thun.

Wenn ich also den localen Charakter dieses zweiten Gesetzes augenblicklich immer noch streng festgehalten wissen und gegen eine Verallgemeinerung desselben vor der Hand immer noch Bedenken äussern möchte, so darf ich doch nicht unterlassen, auf die Resultate hinzuweisen, welche Holmgren bei seinen so sehr umfangreichen Untersuchungen gewonnen hat. Unter dem 3. Juli 1878 schrieb mir dieser Forscher über den fraglichen Punkt: „In Bezug auf die Thatsachen, auf welche Sie Sich stützen, habe ich auch Aehnliches gefunden, glaube aber, dass sehr grosse Tabellen dazu gehören, um sicher zu sein." Eine specielle Uebersicht über diese seine Resultate hat nun Holmgren jüngst auch gegeben und stellen sich dieselben folgendermassen:

*) a. a. 0 .

v. Graefe's Archiv fur Ophthalmologin, XXIY, 4. 


\begin{tabular}{|c|c|c|c|c|c|c|}
\hline Stand. & Zahl. & $\begin{array}{r}\text { Far } \\
\text { bl } \\
\text { vollst } \\
\text { Roth. }\end{array}$ & $\begin{array}{l}\text { en- } \\
\text { nd } \\
\text { ndig. } \\
\text { Grün. }\end{array}$ & $\begin{array}{c}\text { On- } \\
\text { voll- } \\
\text { stän- } \\
\text { dig. }\end{array}$ & Summa. & 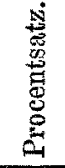 \\
\hline Volksschuler ... & 3654 & 36 & 51 & 79 & 166 & 4,54 \\
\hline Elementarschüler . & 8682 & 83 & 72 & 145 & 300 & 3,45 \\
\hline $\begin{array}{l}\text { Studenten . . . . } \\
\text { Junge Leute ver }\end{array}$ & 1523 & 8 & 13 & 26 & 47 & 3,08 \\
\hline $\begin{array}{l}\text { Junge Leute ver- } \\
\text { schiedenerStände }\end{array}$ & 555 & 6 & 7 & 12 & 25 & 4,50 \\
\hline Eisenbahnpersonal & 7953 & 45 & 48 & 78 & 171 & 2,15 \\
\hline Seeleute ... . . . & 4225 & 22 & 30 & 42 & 94 & 2,22 \\
\hline Soldaten . . . . . & 1851 & 13 & 20 & 29 & 62 & 3,54 \\
\hline Fabrikarbeiter .. & 649 & 9 & 4 & 18 & 31 & 4,77 \\
\hline Gefangene . . . & 321 & 5 & 4 & 9 & 18 & 5,60 \\
\hline
\end{tabular}

Werfen wir einen Blick auf Zeile 1, 2 und 3 dieser Tabelle, so wird uns ein Unterschied bemerkbar werden, wie ihn meine Untersuchungen in auffallend ähnlicher Weise ergeben haben. Es wird hierdurch die Möglichkeit eröffnet, dass die von mir gefundenen, für die Breslaner Verhältnisse vor der Hand ausschliesslich gültigen That. sachen auch eine allgemeinere Bedentung erlangen könn. ten. Doch bleibt das entscheidende Wort in dieser Frage späteren umfangreichen Untersuchungen vorbehalten.

Das dritte unserer Gesetze lautete:

Die Juden haben eine grössere Neigung und Anlage zur Farbenblindheit, als die Christen. Auch diese Thatsache hat vor der Hand erst nur einen localen Character, insofern durch Cohn's, sowie durch meine Untersuchungen eine grössere Verbreitung der Farbenblindheit speciell unter den Breslauer Juden sich herausgestellt hat. Cohn und ich fanden zusammen unter 814 jüdischen Schülern 34 Farbenblinde, also $4,1 \%$ während wir unter 1947 christlichen Knaben nur 42 Farben. blinde fanden, also 2,1\%. Nach meinen späteren Unter- 
suchungen fand ich unter 3273 Individuen 100 farbenblind, d. h. $3,27 \%$; davon waren 2509 Christen mit 71 Farbenblinden, d. h. $2,83 \%$, während 764 Juden 29 Farbenblinde ergaben, also 3,79\%. Noch auffallender gestaltete sich dies Verhältniss bei den Specialuntersuchungen, welche ich grade über diesen Gegenstand anzustellen Gelegenheit hatte. Zwei, ausschliesslich nur von jüdischen Kindern besuchte Religionsschulen enthielten nämlich unter 216 Knaben 11 Farbenblinde, d. h. also $5,09 \%$. Nach den neuesten Mittheilungen Cohn's*) stellt sich das eventuelle Verhältniss zwischen den Breslauer Juden und Christen bezüglich der Farbenblindheit wie $4,8: 3,6 \%$. Doch beziehen sich alle diese Thatsachen lediglich nur auf das männliche jüdische Geschlecht, während dagegen der weibliche Theil der Breslauer jüdischen Bevölkerung eine ebenso geringe Neigung zur Farbenblindheit enthüllte, wie ihre christlichen Schwestern.

Es drängt sich uns nun die Frage auf: ist diese von uns nachgewiesene Neigung der Breslauer Juden zur Farbenblindheit eine allgemeine Stammes- resp. Racen. eigenthümlichkeit der Juden überhaupt, oder ist sie nur ein zufälliges Vorkommniss, dass in irgend welchen rein localen Verhältnissen unserer Stadt seine Erklärung findet? Wenn nun auch die Beantwortung dieser immerhin nicht unwichtigen Frage solange mit Sicherheit nicht zu geben ist, als noch einschlägige Mittheilungen anderer Untersucher fehlen, so dürfte es doch gestattet sein, gewisse Vermuthungen über diesen Pankt zu äussern; besonders wenn diese Vermuthungen zugleich eine Erklärung für meinen Befund geben sollen.

Ich bin nämlich nicht abgeneigt, den eigenthümlichen Befund, den Cohn sowie ich in gleicher Weise hier in Breslau festgestellt haben, auf gewisse Eigenthümlich-

*) a. a. 0 . 
keiten des jüdischen Volkes überhaupt zurückzuführen. Die ausgesprochene Vorliebe, mit welcher der Jude Ehen nur mit Stammesverwandten eingeht und sich vor jeder Vermischung mit fremdem Blut behïtet, muss ja, besonders wenn derartige Rücksichten durch Jahrhunderte hindurch ängstlich gewahrt werden, zu einem fast absoluten Ausschluss neuen Blutes führen, eine Erscheinung, wie wir sie in diesem Umfang gewiss nicht bei einem anderen Volk Europa's wiederfinden werden. Die Vermischung verwandten Blutes muss bei der ohnehin nicht allzu grossen numerischen Ausbreitung des jüdischen Volkes Dimensionen erreichen, wie sie bei den Christen wohl nur selten vorkommen werden. In dieser Häufung von Verwandtenehen oder besser gesagt, in dem energischen Abschluss gegen jede Zuführung neuen und fremden Blutes, würde aber nach unseren heutigen Anschauungen schon allein ein Moment gegeben sein, welches zum Auftreten physiologischer Abnormitäten von vornherein prädisponiren könnte. Erinnern wir uns nun noch, dass grade die Farbenblindheit eine so hochgradige Neigung zeigt, sich auf dem Wege der Vererbung zu verbreiten, so ist es eigentlich sebr natürlich, wenn grade die Juden durch ihre immerwährend sich wiederholenden Ehen unter und mit einander dies erbliche Moment der Farbenblindheit in ihren Kreisen, wenn man so sagen darf, gradezu züchten und aus diesem Grunde mehr zur Farbenblindheit neigen müssen, als wie die Christen. Natürlich könnte aber diese Anschauung nicht mehr bloss zu einer Erklärung der localen Breslauer Verhältnisse benutzt werden, sondern sie müsste eine allgemeinere Bedeutung erhalten und uns zu der Annahme führen, dass die Anlage zur Farbenblindheit als eine Raceneigenthümlichkeiten der Juden aufzufassen sei. Inwieweit nun diese Vermuthung eine Bestätigung durch andere Forscher finden wird, muss noch abgewartet werden und deshalb 
thut man wohl gut, sich auch dieser Frage gegenüber vor der Hand, bis noch ein grösseres statistisches Material gesammelt worden ist, noch mit einer gewissen Reserve zu verhalten; besonders da sich sämmtliche Angaben, welche bisher über die grössere oder geringere Neigung gewisser Nationen zur Farbenblindheit gemaeht worden sind, den neueren Untersuchungen gegenüber als nicht stichhaltig erwiesen haben. Es hat sich gezeigt, dass weder die Germanen eine ganz besondere Prädispostion zur Farbenblindheit haben, wie einzelne Autoren behauptet haben, noch dass sich die romanischen Völker einer gewissen Immunität diesem Gebrechen gegenüber erfreuen können, wie wieder andere Forscher vermuthet haben.

§5. Eintheilung der Farbenblindheit nach ihren Graden.

Wenden wir uns nunmehr zu einer genaueren Betrachtung der einzelnen von uns entdeckten Fälle von Farbenblindheit, so dürfte es sich empfehlen, dieselben hauptsächlich nach zwei Gesichtspunkten hin zu untersuchen: nämlich einmal zu prüfen, in welcher Intensität dieser Fehler des Farbensinnes bei den verschiedenen Individuen sich fand und dann welcher Art derselbe war.

Fassen wir nun zuvörderst den ersten Punkt in's Auge, so thun wir am Besten, uns der von Holmgren aufgestellten Eintheilung anzuschliessen und vier Intensitätsgrade der Farbenblindheit anzunehmen, nämlich:

1) Totale Farbenblindheit, ein Zustand, bei welchem dem betreffenden Individuum jede Farben. empfindung fehlt.

2) Vollständige Farbenblindheit; hierbei fehlt nur die Fähigkeit, eine der drei Grundempfindungen Roth, Grün, Violett richtig zu percipiren. In welcher Weise die Farbenempfindung im Allgemeinen durch einen derartigen A usfall einer Grundempfindung modificirt wer- 
den muss, ist bereits von Helmholtz und Holmgren erörtert worden und können wir unter Hinweis auf die einschlägige Literatur diesen Punkt nunmehr fallen lassen. Diese vollständige Farbenblindheit zerfällt je nach der Grundfarbe, die nicht empfunden wird, in:

a) Violettblindheit;

b) Grünblindheit;

c) Rothblindheit.

3) Unvollständige Farbenblindheit. Dieser Zustand boruht in einer geminderten Empfindlichkeit gegen eine der drei Grundfarben. Derartige Farbenblinde erkennen die gesättigten Töne der betreffenden Farbe noch leidlich, so z. B. Seharlach, während ihnen dagegen die Empfindung der dunkleren oder helleren Nuancen dieser Farbe Schwierigkeiten bereitet. Ist dieser Zustand in einer ausgeprägteren Form vorhanden, so kann der Untersucher ohne sonderliche Schwierigkeit einen Unterschied zwischen unvollständiger Violett, Grün- und Rothblindheit machen. Und aus diesem Grunde kann man derartige Fälle als: ,a usgeprägte Formen der unvollständigen Farbenblind heit" bezeichnen. Uebrigens scheinen diese Formen der unvollständigen Farbenblindheit viel häufiger vorzukommen, als wie die Fälle vollständiger Farbenblindheit. Neben diesen höheren Formen der unvollständigen Farbenblindheit existiren anch noch zahlreiche niedere Grade, welche Holmgren als "schwachen Farbensinn" bezeichnet hat. Diese niederen Formen zeichnen sich im Allgemeinen dadurch aus, dass die Empfindlichkeit für eine Farbe nur insoweit gestört ist, als es sich um das Erkennen beller Schattirungen handelt. Die ausgesprochenen Nüancen werden dagegen schnell und sicher erkannt. Die geringsten Grade dieses schwachen Farbensinnes bieten eben in Folge ihrer meist unbedeutenden Erscheinungsmerkmale der Diagnose gewisse Schwierigkeiten dar. Der Unter- 
sucher kann diese Formen nur allzu leicht übersehen, und bei Individuen einen völlig normalen Farbensinn diagnosticiren, bei denen in Wahrheit doch eine Farbenschwäche vorhanden ist. Einen genügenden Schutz gegen derartige Irrthümer, die einem wenig geübten Untersucher nur allzu leicht passiren können, bietet uns aber die Holmgren'sche Methode. Leitet man die Untersuchung mit hellgrüner Wolle ein, so wird man sicher sein, alle auch die niedrigsten Grade des schwachen Farbensinnes zu entdecken. Ich habe in vielen Fällen mich von dieser Thatsache durch Controlversuche überzeugt, indem ich den betreffenden Individuen statt hellgrüner Wolle zuerst hellrosa Wolle vorlegte. Hierbei habe ich nämlich wiederholt beobachtet, dass eine ganze Reihe von Individuen $\mathrm{zu}$ der vorgelegten hellrothen Probe die identischen Wollen heraussuchten, die Einen schnell und sicher, die Anderen zögernd und langsam; legte man ihnen aber alsdann hellgrüne Wolle vor, so documentirte sich ihr Fehler alsbald in klarster Weise. Derartige Erfahrnngen haben vielleicht $\mathrm{Holmgren}$ dazu bestimmt, die Untersuchung mit Vorlage von bellgrüner Wolle zu beginnen.

4) Farbenträgheit. Diese Rubrik habe ich der Holmgren'schen Eintheilung, welche eigentlich nur 3 Intensitätsgrade der Farbenblindheit kennt, neu hinzugefügt; man könnte die hierher gehörigen Formen zwar schliesslich auch nur als Formen des schwachen Farbensinnes ansehen, doch schien mir ihre Auffassung als selbstständige Art, welche zwischen dem normalen Farbensinn und der Farbenblindheit steht und den Uebergang von jenem $\mathrm{zu}$ dieser vermittelt, empfehlenswerther. Die Farbenträgheit charakterisirt sich in folgender Weise: das betreffende Individuum legt bei schneller Untersuchung, z. B. in der Schule, genan in derselben Weise die Wollenproben zusammen, wie ein wirklich Farbenblinder 
Und zwar ist dies nicht etwa bloss der Fall bei Prufung mit hellen Farbentönen, sondern auch bei Vorlage dunklerer und gesättigterer Nüancen. Hierdurch scheint sich eben die Farbenträgheit von den leichtesten Fällen des schwachen Farbensinnes zu unterscheiden, in denen nur bei hellen Schattirungen Irrthümer begangen werden. Examinirt man nun aber ein farbenträges Individuum eingehend und fordert es auf, langsam und nur nach eingehendster Prüfung die Wollenproben zu sortiren, so stellt sich alsbald heraus, dass sein Farbensinn ein ganz normaler ist. Die betreffende Person vermag alsdann jeden Farbenton richtig zu erkennen, wohl auch richtig zu benennen und verfällt in ihren Fehler immer nur dann, wenn das Sortiren der Wollen schnell und ohne die gehörige Sorgfalt vorgenommen wird. Und zwar sind die begangenen Fehler und Irrthümer immer genau dieselben, wie sie sich ein wirklich Farbenblinder zu Schulden kommen lässt. Dieser Umstand unterscheidet derartige Individuen wesentlich von solchen, die bloss aus Faselei Fehler begehen; denn bei diesen letzteren zeigen die Fehler niemals einen bestimmten, immer wiederkehrenden Typus, wie dies bei jenen der Fall ist. Es will mir fast scheinen, als ob die Farbenträgheit in den niederen Schulen ein häufigeres Vorkommniss sei, als wie in den höheren. Doch möchte ich grade diesen Punkt nur mehr als eine blosse Vermuthung angesehen wissen. Im Uebrigen bin ich geneigt, die Farbenträgheit als das Uebergangsstadium vom normalen Farbensinn zur Farbenblindheit anzusprechen.

Natürlich giebt es sowohl innerhalb dieser $4 \mathrm{Ab}$ stufungen der Farbenblindheit, als auch zwischen denselben eine ganze Reihe der verschiedensten Uebergangsformen, welche einer derartigen Eintheilung immer, wenigstens bis zu einem gewissen Grade, einen subjectiven Charakter verleihen. Es geht ferner auch aus unseren 
Betrachtungen hervor, dass zwischen Farbenblindheit und normalem Farbensinn keineswegs eine tiefe unüberschreit. bare Kluft besteht; viclmehr geht der normale Farbensinn durch eine ganze Reihe von allmählichen Uebergangsformen unmerklich in die Farbenblindheit über. Aus diesem Grunde ist auch die Frage, wo hört die Farbenblindheit auf und wo fängt die normale Farbenempfinduug an, durchaus nicht etwa so leicht zu beantworten, wie man dies vielleicht von Haus aus sich vor= gestellt haben mag. So ist es z. B. sehr schwierig zu entscheiden, ob jene Formen, welche ich als Farbenträgheit bezeichnet habe, bei denen also die betreffenden Individuen nur bei eiliger und nicht sorgsamer Auswahl der Wollenproben die gleichen Fehler, wie ein wirklich Farbenblinder begehen, sich aber bei ruhiger und überlegter Prüfung als völlig normalsichtig erweisen, bereits der Farbenblindheit zugerechnet werden müssen, oder noch in die Grenzen eines physiologisch normalen Farbensinnes gehören. Offenbar ist bei ihnen der Farbensinn doch nicht so organisirt, um eben so schnell und sicher die Farben zu unterscheiden und farbige Wollenbündel zu sortiren, wie bei anderen Individuen. Ihre Farbenempfindung ist eben eine träge, langsamere, als bei anderen Individuen und giebt darum zu Irrthümern Veranlassung, sobald ein schnelles Urtheil über Farbenqualitäten gefordert wird. Es ist somit also die Grenze zwischen normalem und defectem Farbensinn eine unge. mein flussige und es wird immer dem subjectiven Ermessen des Untersuchers mehr oder minder überlassen bleiben müssen, ob er die Merksteine dieser Grenze mehr nach dem Gebiet des physiologischen oder patho. logischen verrücken will. Daraus geht nun aber wieder mit Sicherheit hervor, dass die Zablen, welche die verschiedenen Untersucher gefunden und die Procentsätze, die sie aus denselben berechnet haben, doch nicht den 
Thatbestand mit absoluter Sicherheit repräsentiren können, sondern zum Theil durch die subjective Auffassung des Untersuchers beeinflusst werden müssen. Wenn dieser Umstand nun auch praktisch von nicht allzu grosser Bedentung sein dürfte, da es ja bei Fixirung der Grenze zwischen normalem und anomalem Farbensinn sich immer nur darum handeln kann, ob man ganz leichte, praktisch nicht in Frage kommende Formen der Farbenblindheit noch als physiologisch oder bereits als abnorm anzusehen habe, so glaube ich doch, dass man die von uns soeben erörterten Thatsachen durchaus nicht obne Weiteres ignoriren darf. Bei Untersuchungen, die einen rein praktischen Zweck haben, also z. B. bei Prüfungen des Farbensinnes von Beamten einer Eisenbahnlinie u. dergl., werden jene Thatsachen gewiss nur nebensächlich in Betracht gezogen werden brauchen, während sie dagegen bei jenen Untersuchungen, welche einen specifisch wissenschaftlichen Charakter tragen, durchans berücksichtigt werden müssen.

Nach diesen Vorbemerkungen werden wir uns nunmehr an eine genauere Besprechung der von uns unterschiedenen 4 Abstufungen der Farbenblindheit begeben können.

\section{Totale Farbenblindheit.}

Unter 106 Farbenblinden *) habe ich 2 total Farbenblinde gefunden, nämlich einen Knaben und ein Mädchen. Und zwar war dies Mädchen - nebenbei bemerkt das einzige farbenblinde Mädchen, welches ich überhaupt gefunden habe. Beide zeigten für alle Farben eine gleichmässige Unempfindlichkeit. Sie vermochten bei der

*) Von meinen 112 Farbenblinden haben sich 6 einer genaueren Untersuchung entzogen, so dass ich bei ihnen nur die Existenz der Farbenblindheit, aber keine näheren Einzelheiten feststellen konnte; dies war ich nur bei 106 im Stande. 
Holmgren'schen Probe keine einzige Farbe richtig zu sortiren und ebenso bewiesen sie am Spectroscop die gleiche Unbehulflichkeit. Den Knaben konnte ich Herrn Dr. Daae aus Norwegen bei seiner diesjährigen Anwesenheit in Breslau vorstellen.

2. Vollständige Farbenblindheit.

Vollständig Farbenblinde habe ich in Summa 30 gefunden und zwar 1 Violettblinden, 19 Grün- und 10 Rothblinde.

3. Unvollständige Farbenblindheit.

Von den ausgeprägten Formen dieser Abtheilungen wurden 55 gefunden, nämlich 6 Violett-, 29 Grün-, 20 Rothblinde. Die Diagnose gründete sich in allen diesen Fällen darauf, dass die betreffenden Individuen im Stande waren, einzelne mehr oder minder ausgesprochene und gesättigte Farbentöne noch za crkennen, dagegen sofort in Verlegenheit geriethen, sobald es sich darum handelte, hellere oder dunklere Schattirungen zu unterscheiden. Bei der spectroscopischen Untersuchung dieser Farbenblinden ergaben sich allerlei Erscheinungen. Einzelne nannten die isolirten Spectralfarben, also z. B. die einzelne Lithiumlinie, ganz richtig roth, oder die Thalliumlinie grün; sobald man sie dann aber aufforderte, die identischen Wollenproben herauszusuchen, trat ihr Fehler in Erscheinung; sie legten dann stets die falschen Farben heraus, also für die Lithiumlinie rothbraun oder grün u. s. w. Andere wieder nannten bei intensiver Beleuchtung die einzelven isolirten Farben richtig und suchten für dieselben auch die entsprechenden Wollenproben heraus; sobald ich aber die Intensität der Beleuchtung etwas dämpfte, waren sie nun nicht mehr im Stande, sich über die Beschaffenheit der vorliegenden Farbe zu äussern oder suchten für dieselbe falsche 
Wollenproben heraus. Von einer dritten Art, und diese Beobachtung habe ich sehr hänfig gemacht, wurden die isolirten Spectralfarben leidlich erkannt; zwar irrten sich die betreffenden Individnen ab und zu sowohl in der Auswahl der für die vorliegende Spectralfarbe identischen Wollenproben, als auch im Namen der Spectral. farbe, doch gelang es ihnen meist schliesslich nach mehreren vergeblichen Versuchen das Richtige zu treffen. Und zwar war dies bei Einzelnen eher, bei Anderen später der Fall. Auffallend waren dagegen ihre Angaben, sobald man ibnen ein volles Spectrum vorlegte. Hier verschwanden ihnen die Irrfarben zuerst vollständig und sie behaupteten (dies gilt für die Rothsowie die Grünblinden) nur Blau und Gelb zu sehen; bei wiederholter Untersuchung gelang es dann immer, an Stelle der Irrfarben im Spectrum einen Ton zu sehen, der entweder nur als ein Helligkeitsunterschied oder als cine Farbe bezeichnet wurde. War das letztere der Fall, so entsprach die Farbe meist derjenigen, welche die perverse war; also z. B. für die Thalliumlinie bellroth oder grau a. s. w. Nicht selten wurden aber auch nur graue oder bräunliche Wollenproben als identisch mit der Irrfarbe heraus gesucht. In noch anderen offenbar noch leichteren Fällen wurden die isolirten Spectral. farben richtig erkannt und durch richtige Wollenproben gekennzeichnet; wurde aber dann das volle Spectrum vorgelegt, so fiel nur die betreffende Farbe, fur die das Individuum mehr oder minder unempfindlich war, aus; so wurde z. B. in dem einen Fall die Lithiumlinie ganz richtig durch roth und die Thalliumlinie durch grün mar* kirt, nachdem letztere erst ein Mal durch braune Wolle bezeichnet worden war. Im vollen Spectrum wurde aber an Stelle des Grün Grau gesehen, während Roth richtig erkannt wurde. In noch leichteren Fällen wurde die Lithium- und Thalliumlinie richtig erkannt, doch sollte 
das volle Spectrum nur aus zwei Farben, Blau und Gelb, bestehen. Erst wenn man das betreffende Individuum wiederholt, untersucht und darauf aufmerksam gemacht hatte, dass im Spectrum ausser Blau und Gelb noch andere Farben vorhanden wären, wurde auch noch Roth und Grün bemerkt und schliesslich auch durch die passenden Wollenproben charakterisirt.

Interessant waren mir die subjectiven Beobachtungen, welche einzelne dieser unvollständig Farbenblinden an sich selbst gemacht hatten. So berichtete mir z. B. einer derselben, dass er bei Spaziergängen im Freien, auf Wiesen und in Wäldern, hauptsächlich die gelb gefürbten Blumen wahrnähme; diese fielen ihm ganz besonders auf, während sich ihm die andersfarbigen weniger bemerkbar machten. Dieser Umstand hätte auch besonders dazu beigetragen, seine Farbenblindheit zu entdecken. Denn es sei ihm wiederholt passirt, dass er Bouquets von lauter gelben Blumen gepfiückt und nach Hause gebracht habe, und da er in dem Glauben, eine Collection schön gefärbter Feldblumen gesammelt zu haben, sich in diesem Sinne geäussert hätte, so sei er verlacht und verspottet worden. Da ihm dies zu wiederholten Malen begegnet sei, so wäre er schliesslich stutzig geworden und bätte sich nun durch weitere Beobachtungen von seiner Farbenblindheit überzeugt. Ein Anderer, ein sehr inteligenter Lehrer, welcher seinen Zustand genau studirt hatte, erzählte mir: dass er sich schon lange von seinem Fehler überzeugt hätte. Und zwar wisse er, dass er die Farben nur dann er. kennen und auch ziemlich sicher unterscheiden könne, wenn sie eine grössere Sättigung besässen; wäre dies aber nicht der Fall, wären die Pigmentfarben stark mit Weiss oder Schwarz gemischt, so verliere er sofort die Fähigkeit, diese Schattirungen noch als Farben za empfinden. Dann könne er nur verschiedene Helligkeits- 
grade unterscheiden und diese benütze er auch, sobald er genöthigt würde, derartige Farbennüancen $\mathrm{zu}$ benennen. Die helleren Töne erschienen ihm als verschiedene Arten von Grau, während die dankleren Farben ihm eben nur durch ihren Lichtmangel imponirten. Desshalb erklärte dieser Farbenblinde aueh, dass er den Homerischen Vergleich eines dunkelfarbigen Haupthaares mit einem Veilehen für ganz treffend erachte; denn die Farbe des Veilchens erschiene ihm in der That nur dunkel.

Die leichteren Formen der unvollständigen Farbenblindheit, welche ich unter dem Begriff des schwachen Farbensinnes zusammengefasst habe, charakterisiren sich - wie bereits bemerkt - hauptsächlich durch eine herabgesetzte Empfindlichkeit gegen hellere Farbentöne. Ich zähle im Augenblick nur 20 derartige Fälle, muss aber bemerken, dass diese Zahl eigentlich nicht dem factischen Thatbestand entspricht, sondern nur einen mehr subjectiven und individuelien Werth beanspruchen darf. Ich habe nämlich in meine Statistik nur die ausgesprocheneren Fälle des schwachen Farbensinnes aufgenommen, die geringsten Grade aber als mehr der normalen Empfindungssphäre angehörig ausgeschlossen. Ich glaube damit den Werth meiner Statistik in keiner Weise beeinträchtigt zu haben; denn, wie ich bereits Eingangs meiner Arbeit erwähnt habe, ist gerade die Beurtheilung der leichten Formen der Farbenblind. heit immer eine mehr oder minder individuelle und der Willkür des Untersuchers anheimgegebene. Aus diesem Grunde wird meine Statistik, sowie auch die eines jeden anderen Untersuchers bis zu einem gewissen Grade immer nur einen relativen Werth beanspruchen können, den wirklichen Thatbestand immer nur relativ, aber nicht absolut repräsentiren.

Die ausgesprochene Farbenschwäche charakterisirt sich also in einer Unempfindlichkeit gegen ganz helle 
Töne; meist sind es Schattirungen, welche den auf der Holmgren'schen Tafel unter I. und $1-5$. abgebildeten entsprechen. Man kann übrigens hier 2 Formen unterscheiden; die Einen verwechseln hauptsächlich Grau mit Fleischfarbe, die Anderen dagegen Grün mit Braun*). Es erscheinen in derartigen Fällen alle hellen Töne von Roth wirklich als Grau; die betreffenden Individuen nennen auch Fleischfarbe grau; bei der anderen Form werden gewisse helle Schattirungen von Grün als Braun bezeichnet. Bei der spectroscopischen Untersuchung werden von diesen Farbenblinden aber keinerlei Irrthümer begangen. In anderen Fällen legen die botreffenden Individuen zu fleischfarbener oder zu grüner Wolle grau, resp. braun. Macht man sie alsdann auf ihren Irrthum aufmerksam, so merken sie wohl, dass sie einen Fehler begangen haben, finden aber doch gewisse Schwierigkeiten, die fälschlich zusammengelegten Nüancen richtig zu sortiren. Noch Andere, und dies sind offenbar die leichtesten Fälle, die ich in meine Statistik überhaupt nicht mehr aufgenommen habe, greifen, legt man ihnen bei der Holmgren'schen Probe Hellgrün oder Fleischfarbe vor, wiederholt nach Grau resp. Braun und legen auch die fälschlich herausgegriffenen Nüancen neben die betreffenden Probe; sobald aber nun die bräunliche Wolle neben der hellgrünen oder die graue Wolle neben der fleischfarbenen liegt, überzeugen sie sich von ihrem Irrthum und verwerfen die falschen Nüancen sofort wieder. Auf eine Faselei sind derartige Irrthümer gewiss nicht zurückzuführen. Denn hierbei, davon wird sich Jeder überzengen, der zahlreiche einschlägige Untersuchungen ausgeführt hat, kehren die Irrthümer niemals

*) Diese Form bezeichnet Holmgren als unvollkommene Farbenblindheit. 
in den charakteristischen Typen wieder, wie bei derartigen, mit schwachem Farbensinn behafteten Individuen.

\section{Farbenträgheit.}

Diesen Zustand haben wir schon auf den vorigen Seiten genügend charakterisirt und können wir deshalb von einer weiteren Besprechung desselben hier absehen.

\section{\$6. Fintheilung der Farbenblindheit nach}

\section{ihren Arten.}

Hinsichtlich der Fintheilung der Farbenblindheit nach ihren Arten herrscht augenblicklich unter den verschiedenen Autoren nur wenig Uebereinstimmung; während die Einen mit Helmholtz und Holmgren eine Roth-, Grün- und Violettblindheit annchmen, wollen Andere nur eine Roth-Grün- und Blau-Gelbblindheit gelten lassen. .Und da beide Partheien im Stande sind, fur ihre Ansicht theoretische wie praktische Beweismittel beizubringen, so scheint der Streit vor der Hand wohl noch einer allgemeinen endgültigen Lösung ziemlich fern" zustehen. Ich für meine Person bin geneigt, eine Roth-, Grün- und Violettblindheit anzunebmen, and wenn es mir auch in einzelnen Fällen nicht gelingen wollte, diese Diagnose streng durchzoführen, so kann mich dies doch nicht von dem absolut Irrthümlichen dieser Eintheilung uberzengen. Ich habe gefunden, dass die Aufstellung einer Roth-Grün- und Geib-Blaublindheit bei der genauen praktischen Untersuchung der einzelnen formen der Farbenblindheit doch nicht in dem Grade stichhaltig ist, dass man ohne jeden Zweifel an der Berechtigung dieses Eintheilungsprincipes durchaus sich genöthigt sehen müsste: die Annahme einer Roth-, Grün- und Violettblindheit als unbedingt falsch zu verwerfen. Ueberdies sprechen die von Holmgren mit seinem Chromatosk- 
iameter*) vorgenommenen Untersuchungen mindestens ebenso für die Aufstellung einer besonderen Roth-, Grünund Violettblindheit, als dies die Behauptungen der Gegenpartei hinsichtlich der Annahme einer Roth-, Grünund Gelb-Blaublindheit thun. Jedenfalls ist die Entscheidung über die Richtigkeit beider Eintheilungsprincipe nicht so leicht, wie dies $\mathrm{Cohn} * *$ ) anzunehmen scheint, wenn er behauptet: die von Helmholtz und Holmgren proponirte Eintheilung sei unhaltbar und wenn man nur sorgsam untersuche, müsse sich Jeder von dieser Unhaltbarkeit überzeugen. Wenn ich diesen Einwurf einer nicht genügend sorgsamen Untersuchung nun mir gegenüber auch nicht sonderlich rügen will, trotzdem ich versichern kann, dass ich bei meinen Untersuchungen mit möglichster Sorgfalt zu Werke gegangen bin, so will es mir doch scheinen, dass man die Ansichten und Erfahrungen Holmgren's, der auf Grund eines langjährigen und eingehenden Studiums der Farbenblindheit zur Aufstellung der Roth-, Grün- und Violettblindheit sich genöthigt gesehen hat, nicht durch den Vorwurf einer ungenügenden und mangelhaften Sorgfalt beseitigen könne. Indem ich für meine Person mir wohl bewusst, bin, dass die Young-Helmholtz'sche Farbentheorie von gewissen physiologischen und praktischen Bedenken nicht frei ist und auch die Aufstellung einer Grîn-, Roth- und Violettblindheit ihren wunden Punkt hat, so will es mir doch so scheinen, als ob die gegnerischen Ansichten mindestens die gleichen Schwächen besässen. Und da ich nun gemäss meiner physiologischen An-

*) Holmgren. Om de färgade skuggorna och färgblindheten. Upsala, 1878 , pag. 31 .

**) Bericht über die Sitzrng der Heidelberger ophthalm. Gesellsellschaft. Beilage zum Angustheft des Centrabl. für praktische Augenheilkunde. 1878, pag. XXXIII.

$\nabla_{+}$Graefe's Archiy fir Ophthalmologie, XXIV. 4. 
schauungen, sowie meiner praktischen Erfahrungen hinsichtlich der Farbenblindheit den Helmholtz-Holmgren'schen Standpunkt unbedingt bevorzuge, so habe ich im Anschluss an die vortrefflichen Leistungen des schwedischen Forschers dessen Eintheilungsprineip acceptirt und nach seinen Vorschriften die Diagnose der Grän, Roth- und Blaublindheit gestellt.

\section{Violettblindheit.}

Ich möchte Stilling*) beipflichten, wenn er behauptet: die Blaublindheit sei durchaus nicht so selten, wie man dies bis jetzt meist anzunehmen geneigt war. Ich habe unter meinen Farbenblinden 7 Violettblinde nachweisen können. Unter diesen war einer vollständig violettblind, während die anderen den mittleren Graden angehörten.

Bei der Holmgren'schen Wollenprobe sortirten die ausgesprochen violettblinden Individuen in der Weise, dass sie zu fleischfarbener Wolle Grau und Hellgelb, sodann zu Purpur Scharlachroth, zu Gelb Hellgrau, zu Blau Grün, zu Grün Blau und zu Violett Grün legten. Und zwar erhielt ich ein derartiges Resultat bei 5 Individuen, während dagegen 2 andere, welche nur geringe Grade der Blaublindheit besassen, sich etwas abweichend gegenüber der Holmgren'schen Probe verhielten. Sie nannten Gelb stets Grau oder Weiss, je nach der Intensität der vorgelegten gelben Wollenprobe, suchten aber nach sorgfältigem Ueberlegen zu Gelb stets nur wieder Gelb heraus. Dagegen legten sie zu blauer Wolle stets Grün, zu Violett wiederum Grün und zwar Dunkelgrün

*) Stilling. Blau-Gelbblindheit mit unverkürztem Spectrum. Centralbl. f. prakt. Augenheilk. 1878. Maiheft, p. 100. 
und zu Grün Blau. Legte man ihnen grüne Wolle vor und fragte sie nach dem Farbennamen derselben, so lautete die Antwort stets: Blau und umgekehrt bei blauer Wolle immer: Grün.

Höchst charakteristisch gestaltete sich ferner auch die wollspectroskopische Untersuchung. Die Lithiumlinie wurde von allen sieben Blaublinden stets roth genannt und durch mehr oder minder gesättigtes Roth gekennzeichnet, nur einer suchte eine braunrothe Wollenprobe heraus. Und zwar ergab sich, dass grade dies Individuum auch eine Herabsetzung seiner Rothempfindung hatte. Die Natriumlinie wurde von dem absolut Blaublinden weiss genannt und durch helles Grau bezeichnet; von den übrigen sechs wurde sie theils weiss, theils bräunlich oder gräulich genannt und entweder durch bräunlichgrane oder durch weisse, einen leichten Stich in's Gelbe zeigende Wollenproben charakterisirt. Die leichteren Fälle suchten aber, trotzdem sie einen falschen Namen für die Natriomlinie gebraucht hatten, doch passende gelbe Wollen heraus. Die Thalliumlinie wurde von allen 7 Individuen übereinstimmend blau genannt; aber während die hoeligradigen Violettblinden auch blaue Wolle als identisch mit der Thalliumlinie heraussuchten, legten die leichtesten Formen der Blaublindheit nur grüne Wolle heraus. Aehnlich war es mit der Indiumlinie der Fall; diese wurde von den meisten durch grüne und nur von 2 Individuen durch blaue Wolle charakterisirt. Eine so hochgradige Verkürzung an dem blauen Ende des Spectrum's, wie sie Stilling*) in einzelnen Fällen nachgewiesen hat, konnte ich bei meinen Blaublinden nicht constatiren; sie empfanden das blaue Licht immer noch als farbiges Licht, allerdings nicht als blaues, sondern als grünes.

*) a. a. 0 . 
Diese Ergebnisse der wollspectroskopischen Untersuchung stimmen mit der Beschreibung, welche Holmgren von dem Spectrum des Violettblinden entwirft, auf das Trefflichste überein.

Wurde nun ein volles Spectrum vorgelegt, so unterschieden einzelne violettblinde Individuen in demselben nur 2 Farben, nämlich: Roth und Grün; während andere 3 wahrnahmen, nämlich: Roth, Weiss oder Hellgrau oder Weiss mit einem Stich in's Gelb oder helles Fleischroth und Grün. Und zwaz waren die höheren Grade der Blaublindheit nicht mehr im Stande, die nebeneinander liegenden spectralen Schattirungen von Grün und Blau von einander $z \mathbf{u}$ unterscheiden und $z \mathbf{u}$ trennen. Grade wie ihnen bei der Holmgren'schen Wollenprobe Grün und Blau als ein Farbenton imponirt hatte und sie darum beide stets zusammengelegt hatten, so hielten sie auch jetzt das nebeneinander liegende spectrale Grün und Blau für denselben Farbenton und charakterisirten denselben durch gräne Wollenproben. Bie geringsten Grade dagegen waren nicht selten im Stande, das spectrale Blau und Grün noch zu differenziren und legten alsdann . für Blau grüne und für grün blaue Wollenbündel heraus. Das Gelb des vollen Spectrums erschien entweder als Weiss, oder Grau, oder auch als ein sehr schwaches Gelb, und wurde gekennzeichnet durch graue oder fleischfarbene Wolle oder wohl auch durch ein helles, unbestimmtes Gelb. Das Roth des vollen Spectrums wurde Roth genannt und durch Purpur oder Scharlach gekennzeichnet*)

*) Wesentlich verschieden von diesen physiologischen Fallen der Violettblindheit ist die bei Sublatio retinae hin und wieder zur Beobachtung gelangende Unempfindlichkeit gegen die brechbareren Lichtsorten. Ich habe wiederholt Farbenblindheit bei Netzhant- 
Was nun die Contrastempfindungen der Blaublinden anlangt, so wurden bei der Benutzung des simultanen Contrastes der meinem normalen Auge als blau impo. nirende Contrast von dem Blaublinden meist als Dunkel oder Schwärzlich bezeichnet und in einzelnen Fällen wohl auch Grün genannt. Der mir als Gelb erscheinende Contrast wurde meist als Weiss gedeutet.

\section{Grünblindheit.}

Grünblindheit wurde im Ganzen $48 \mathrm{Mal}$ gefunden und zwar 19 Mal als vollständige und 29 Mal als unvollständige. Es war mithin Grünblindheit unter meinen Farbenblinden mehr verbreitet, als wie die Rothblindheit, welche in 30 Fällen nachweisbar war. Auf dies häufigere Vorkommen der Grünblindheit hat in der neuesten Zeit wiederum Hirschberg*) aufmerksam gemacht und für dieselbe den Namen der Grün-Amblyopie in Vorschlag gebracht, eine Bezeichnung, welche mit Rücksicht auf das so häufige Vorkommen unvollständiger

ablösung gesehen; ein Fall, der eine besonders intelligente Person betraf, ergab folgendes Resultat. $Z u$ Blau wurden die verschiedensten Töne von Grün gelegt und Blau auch als Grün bezeichnet. Gelb wurde Roth genannt und verschiedene Töne von Roth zu vorgelegten gelben Wollenproben gelegt. Eine andere Person, welche eine viel ausgedehntere Ablösung hatte, nannte blaue sowie grüne Wolle grün und sortirte zu Blau sowohl Grün wie Grau. Legte man ihr graue Wolle vor und frug sie nach der Farbe derselben, so sagte sie: dieselbe kỏnne sowohl grün wie blau sein. Gelb nannte sie hell, dem Roth nahestehend. Dentlich erkannt wurde nur Roth. Im Spectrum wurde nur Roth wirklich empfunden und auch durch scharlachrothe Wolle markirt, während alle anderen Töne im Graa verschwanden.

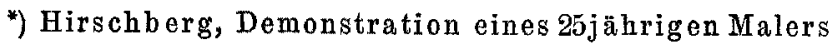
mit angeborener sogenannter Farbenblindheit. Centralblatt für prakt. Augenheilkunde 1878, p. 156. - Holmgren hat unter 39,284 Männern und Frauen 252 Roth- und 277 Grünblinde gefunden. 
Farbenblindheit uns eigentlich besser geeignet erscheinen möchte, als der Ausdruck Grüblindheit.

Die Untersuchung mit den Wollproben ergab die bereits von Holmgren näher beschriebenen Einzelnheiten und will ich deshalb bei diesem Punkt nicht länger verweilen, sondern alsbald zu einer kurzen Besprechung der unter Benutzung der Holmgren'schen Wollenproben ausgeübten wollspektroskopischen Prüfung übergehen.

Die Lithi umlinie wurde durch die verschiedensten Arten von Roth und Gelb gekennzeichnet, beginnend vom gesättigten bis zum hellen dem Orange nahestehenden Ziegelroth; auch Orange wurde für die Farbe des Lithiumroth herausgelegt. In diesen Fallen wurde die orange Wolle stets roth genannt. Sodann wurden für das Lithiumroth auch rothbraune oder bräunliche Wollenproben als identische ausgewählt.

Die Thalliumlinie wurde sehr bäufig durch braune Wollen in der Mehrzahl der Fälle aber durch weisse oder graue Wolle markirt; und zwar wurden alle möglichen Nüancen vom hellsten Grau bis zu den dunkleren Schattirungen ausgewählt; auch Töne, welche ins Gelbliche oder Bläuliche spielten, waren unter diesen grauen Wolleuproben zu bemerken. Auch rothe Wolle wurde mit dem Thalliumgrün als identisch bezeichnet; in einzelnen Fällen wär es ein ganz helles, dem Weiss nahestehendes Fleischroth, in anderen Fällen wieder ein ausgesprocheneres, sich dem Purpur stark näherndes Roth. Sehr oft wurden sowohl für die Lithium-, als auch für die Thalliumlinie Roth herausgelegt, doch war alsdann die dem Lithium entsprechende Nüance nicht selten dunkler und lichtärmer, als die für das Thallium herausgesuchte.

Die Natriumlinie wurde zwar $a b$ und zu Roth genannt, aber in allen Fällen durch gelbe Wolle gekennzeichnet. 
Das volle Spectrum wurde von den meisten Grünblinden auf den ersten Anblick als aus Blan und Gelb oder aus Blau und Roth bestehend geschildert, während dagegen andere Individuen in der Unterscheidung der einzelnen Spectralfarben und deren Schattirungen sich sehr gewandt erwiesen. So erhielt ich z. B. das Spectrum eines Grünblinden, welcher Violett und Blau je durch 2 Töne, Grün durch helles Fleischroth, Gelb durch 2 Schattirungen und Roth durch Orange gekennzeichnet hatte. Doch war eine derartige Beschreibung des Spectrum's immer eine Seltenheit und meist lautete dieselbe dahin: dass im vollen Spectrum nur 2 Farben, Blau und Gelb oder Blau und Roth, vorhanden wären. Viele Grünblinde blieben bei diesem Ausspruch stehen und legten für das volle Spectrum nur gelbe und violette Wollen heraus. Andere dagegen erblickten bei wiederholter Untersuchung*) entsprechend dem spectralen Grün und Roth noch Farben und zwar suchten sie für Grün häufig ein mehr oder minder helles Grau, für Roth Rothbraun oder Roth heraus. Ebenso häufig wurden auch Roth und Grün, beide durch rothe Wolle markirt. In noch anderen Fälen vermochten die betreffenden Individuen zwar von dem Grün des vollen Spectrum's keinen Ein. druck wahrzunehmen, empfanden dagegen das spectrale Roth und legten für dasselbe Braun oder Roth heraus. Das volle Spectrum bestand dann also aus 3 Farben: Violett oder Blau, Gelb, Braun oder Braunroth oder Roth. Das spectrale Blau und Violett wurde meist in eine Empfindung geeint und durch violette oder blaue Wolle ausgedrïckt. Eine derartige feine Empfindung des

*) Das von Hirschberg beschriebene Spectrum (a. a. O., p. 157) würde mit diesem übereinstimmen. 
violetten Endes des Spectrum's, wie wir sie vorhin geschildert haben, gehörte immer nur zu den Ausuahmen. In verschiedenen Fällen wurden auch Spectra angegeben, bei denen das Roth als identisch mil dunklerem Orange, das Orange als heller, und das Gelb als Gelb dargestellt wurden; es. gleichen derartige Spectralbilder dem ron Riccò*) beschriebenen.

\section{Rothblindheit.}

Rothblindheit wurde im Ganzen 30 Mal beobachtet und zwar in 10 Fällen als vollständige, in 20 Fällen als unvollstandige Rothblindheit.

Die Lithiumlinie wurde von 7 vollständig Rothblinden stets durch gräne Wolle gekennzeichnet und zwar durch die verschiedensten Töne, anfangend vom tiefen Dunkelgrün, das dem Schwarz schon sehr nahe kommt, bis zu helleren Schattirungen. Drei von den zebn als vollständig rothblind bezeichneten Individuen verhielten sich bei der Bestimmung der Lithiumlinie abweichend; zwei legten für dieselbe ein mittleres Grau herans, während der andere einen unbestimmten bräunlichen Ton für dieselbe wählte. Der Grund hierfür liegt wohl darin, dass das betreffende Roth für das Auge dieser Rothblinden nicht lichtstark genug war und ihnen deshalb als dunklerer Farbenton imponirte, eine Thatsache, welche auch durch Helmholtz bestätigt wird. Am vollen Spectrum bemerkten diese Rothblinden überhaupt keine Spur vom Roth.

Die höheren Grade der unvollständigen Rothblindheit bevahmen sich bei Bestimmung der Lithiumlinie in ähnlicher Weise; sie legten für dieselbe meist grüne oder

*) Riccò, Studio di un caso di Daltonismo. Annali di oftalmologia. 1876. 
graue Wolle heraus, trotzdem sie dieselbe roth genannt hatten. Die mittleren Grade fanden in der Unterscheidung der Lithiumlinie gleichfalls nicht unbeträchtliche Schwierigkeiten. Sie mussten erst wiederholt in das Spectrum hineinblickén, ehe sie im Stande waren, passende Wollenproben herauszusuchen und auch dann waren dieselben etwa nicht identisch mit dem spectralen Roth, sondern waren heller und fahler, in's Gelblichbraune spielend. Die Thalliumlinie machte derartigen Farbenblinden meist wenig Schwierigkeiten und wurde schnell durch passende grüne Wollenproben markirt. Andere erkannten dic isolirte Lithiumlinie ganz richtig als roth und suchten auch passende Wollenproben heraus, legte man ihnen aber alsdann ein volles Spectrum vor, so war ihre Rothempfindung alsbald gestört und es wurden für Roth grüne Wollenbündel herausgesucht. Noch andere empfanden das lichtstarke spectrale Roth normal, dagegen das lichtschwache als Grün. Die leichtesten Fälle endlich irrten sich bei Vorlage der verschiedenen Spectralfarben nie und verriethen ihren Fehler immer nur gegenüber den nicht sehr ausgesprochenen Pigmentfarben.

Die Natriumlinie wurde von sehr vielen Rothblinden als grün bezeichnet, aber meist durch gelbe Wollen charakterisirt; nur einige Wenige griffen nach grünen Wollen.

Die Thalliumlinie wurde sehr häufig durch grüne Wolle markirt und zwar war dieses Grün in sehr vielen Fällen mit dem völlig identisch, welches für das Lithiumroth herausgesucht worden war, während es in anderen Fällen wicder sich mehr oder minder von jenem unterschied. Gar nicht selten wurde das spectrale Grün ganz richtig als grün bezeichnet, doch vermochte das betreffende Individuum nicht das identische Grün aus den Wollenproben herauszufinden, sondern legte viel- 
mehr stets grau oder braun heraus. War die Rothempfindung nur insoweit gestört, dass das spectrale Roth immer noch als ein rother Ton, wonn auch mit starker Beimischung von Braun empfunden wurde, so wurde das Thalliumgrün fast immer als solches charakterisirt.

Das volle Spectrum machte beim ersten Anblick auf die vollständig Rothblinden, sowie auf die ausgeprägteren Formen der unvollständig Rothblinden stets nur den Eindruck von Blau und Gelb. Und als ein derartiges zweifarbiges wird dasselbe auch von den verschiedensten Autoren geschildert. Doch möchte ich trotzdem im Allgemeinen nicht der Behauptung beipflichten: das Spectrum des Rothblinden sei nur zweifarbig, nämlich blau und gelb; denn bei wiederholter Untersuchung habe ich sehr häufig die Erfahrung gemacht, dass Farbenblinde, die anfänglich nur Blau und Gelb im Spectrum sehen wollten, schliesslich doch noch andere, qualitativ verschiedene Lichtempfindungen wahrnahmen. Der Untersucher muss dabei die Farbenblinden auf die Stellen des Spectrum's, an denen die betreffenden Farben sichtbar sind, aufmerksam machen und seine Prüfung des Oefteren wiederholen. Bei angestrengter Aufmerksamkeit gelingt es alsdann nicht selten, den Rothblinden ausser Blau und Gelb noch andere Farben im Spectrum bemerkbar zu machen.

Entweder empfinden dieselben dann noch am rothen Ende des Spectrum's eine Farbe, die sie nicht näher bezeichnen können und welche sie durch braune Wolle charakterisiren, während sie das spectrale Grün als eine mehr oder minder merkliche Helligkeit beschreiben und graue Wolle dafür heraussuchen. In anderen Fällen sagen sie: es erschiene ihnen am rothen Ende des Spectrum's Roth, für das sie dann aber "Grün" herauslegen und an der Stelle des spectralen Grün ein grauer oder brauner 
Ton, für den sie alsdann gleichfalls grüne oder branne Wolle heraussuchen.

Die Untersuchungen auf Contrastempfindungen scheinen mir im Allgemeinen nur wenig Zatrauen zu verdienen. Denn grade bei ihnen ist der Untersucher den subjectiven Angaben des Farbenblinden unbedingt anheimgegeben und damit einer sehr bedeutenden Fehlerquello ausgesetzt, gegen die er sich kaum in einer nennenswerthen Weise schützen kann. Die intelligenteren der von mir untersuchten Farbenblinden, mochten es nun Roth- oder Grünblinde sein, erklärten häufig, dass sie bei Vorlage von Carmin, Rosa, Grün keine farbige Contrastempfindung zu spüren vermöchten. Sowohl bei Prüfung des Simultanencontrastes, als auch bei Untersuchung der Nachbilder erhielt ich bei Vorlage jener Farben diese Angaben. Die betreffenden Individuen behaupteten stets keine Farbenempfindung, dafür aber einen Lichteindruck zu bemerken, und zwar definirten sie denselben entweder als ein unbestimmtes helles Grau oder belegten ihn überhaupt nur mit dem Ausdruck „hell”. Charakteristischer bezüglich der Qualität der Empfindung gestalteten sich dagegen die Contrasterscheinungen bei Blau und Gelb. Die Contrastfarbe des ersteren wurde meist als gelblich angegeben, während die des Gelb bläulich genannt wurde. Auch erfolgten bei diesen beiden Farben die Antworten meist schnell und prompt, während sie bei den anderen Farben nur zögernd und unsicher herauskamen. Ans diesem Grunde scheint es mir auch empfehlenswerth, jede Untersuchung auf Contrastempfindungen bei Roth oder Grünblinden mit der Vorlage von Gelb und Blau zu beginnen. Die untersuchten Farbenblinden überzeugen sich hierbei, dass die Nachbilder oder der Contrast, den sie empfinden und beschreiben sollen, farbiger Natur ist; beginnt man mit einer anderen Farbe, so wird man meist hören, dass uberhaupt keine farbige Erscheinung zu bemerken sei 
und man wird sich bald überzeugen, dass der betreffende Farbenblinde eigentlich gar nicht recht weiss, um was es sich handelt. Deshalb habe ich bei Roth- und Grünblinden derartige Untersuchungen auch stets mit der Vorlage von Blau und Gelb begonnen, während ich bei Violettblinden mit Roth anzufangen pflegte.

Von anderen Farbenblinden erhielt ich allerdings nähere Angaben über die Qualitäten ihrer Contrastempfindungen, doch boten derlei Mittheilungen nichts sonderlich Bemerkenswerthes dar, bewiesen vielmehr nur auf's Neue, wie schwankend, widersprechend und unzuverlässig das subjective Urtheil eines Farbenblinden über Farbenempfin. dungen ist. Ich verzichte deshalb auch darauf, die subjectiven Angaben, welche meine Farbenblinden hinsichtlich ihrer Contrastempfindungen machten, ausführlich mitzutheilen und möchte alle derartige Untersuchungsmethoden überhaupt nur dann für wirklich brauchbar erklären, wenn sie eine objective Controle auszuüben vermögen. 